\title{
Stress-induced phosphoprotein 1 acts as a scaffold protein for glycogen synthase kinase-3 beta-mediated phosphorylation of lysine-specific demethylase 1
}

\author{
Chia-Lung Tsai ${ }^{1}$, An-Shine Chao ${ }^{2}$, Shih-Ming Jung ${ }^{3}$, Chiao-Yun Lin ${ }^{4}$, Angel Chao ${ }^{2,4}$ and Tzu-Hao Wang ${ }^{2,4}$
}

\begin{abstract}
Stress-induced phosphoprotein 1 (STIP1) - a co-chaperone of heat shock proteins-promotes cell proliferation and may act as an oncogenic factor. Similarly, glycogen synthase kinase-3 beta (GSK3ß)-mediated phosphorylation of lysine-specific demethylase 1 (LSD1) —an epigenetic regulator — can contribute to the development of an aggressive cell phenotype. Owing to their ability to tether different molecules into functional complexes, scaffold proteins have a key role in the regulation of different signaling pathways in tumorigenesis. Here, we show that STIP1 acts as a scaffold promoting the interaction between LSD1 and GSK3 3 . Specifically, the TPR1 and TPR2B domains of STIP1 are capable of binding with the AOL domain of LSD1, whereas the TPR2A and TPR2B domains of STIP1 interact with the kinase domain of GSK3 3 . We also demonstrate that STIP1 is required for GSK3 $\beta$-mediated LSD1 phosphorylation, which promoted LSD1 stability and enhanced cell proliferation. After transfection of cancer cells with double-mutant (S707A) S711A) LSD1, subcellular localization analysis revealed that LSD1 was translocated from the nucleus to the cytoplasm. In vitro experiments also showed that the LSD1 inhibitor SP2509 and the GSK3 3 inhibitor LY2090314 acted synergistically to induce cancer cell death. Finally, the immunohistochemical expression of STIP1 and LSD1 showed a positively correlation in human cancer specimens. In summary, our data provide mechanistic insights into the role of STIP1 in human tumorigenesis by showing that it serves as a scaffold for GSK3 $\beta$-mediated LSD1 phosphorylation. The combination of LSD1 and GSK3 $\beta$ inhibitors may exert synergistic antitumor effects and deserves further scrutiny in preclinical studies.
\end{abstract}

\section{Introduction}

Stress-induced phosphoprotein 1 (STIP1, also known as heat shock protein [HSP] 70/90 organizing protein, Gene ID 10963) is a $62.6-\mathrm{kDa}$ protein that acts as a cochaperone of HSPs. It is structurally characterized by the presence of three tetratricopeptide repeat (TPR) domains as well as two domains rich in aspartate and proline (DP

Correspondence: Angel Chao (angel945@cgmh.org.tw) or T-

H. Wang (knoxtn@cgmh.org.tw)

'Genomic Medicine Research Core Laboratory, Chang Gung Memorial Hospital, Taoyuan, Taiwan

2Department of Obstetrics and Gynecology, Chang Gung Memorial Hospital, Linkou Medical Center and Chang Gung University, Taoyuan, Taiwan

Full list of author information is available at the end of the article domains $)^{1,2}$. Within the HSP90 chaperone machinery, the TPR and DP2 domains are capable of interacting with the HSP90 and HSP70 proteins $^{3-5}$. Knockout mice lacking STIP1 are embryonic lethal, suggesting a key developmental role for this molecule ${ }^{6}$. Growing evidence also indicates that STIP1 is markedly overexpressed in various human solid malignancies ${ }^{7-13}$. Conversely, its repression blocks both tumor cell proliferation ${ }^{11}$ and migration ${ }^{14}$. At the molecular level, the anticancer effect of STIP1 blockade is accompanied by a decreased expression of HSP90 client proteins ${ }^{14}$ as well as inhibition of the JAK2STAT3 pathway ${ }^{5}$.

\section{(c) The Author(s) 2018}

(c) (i) Open Access This article is licensed under a Creative Commons Attribution 4.0 International License, which permits use, sharing, adaptation, distribution and reproduction cc) in any medium or format, as long as you give appropriate credit to the original author(s) and the source, provide a link to the Creative Commons license, and indicate if changes were made. The images or other third party material in this article are included in the article's Creative Commons license, unless indicated otherwise in a credit line to the material. If material is not included in the article's Creative Commons license and your intended use is not permitted by statutory regulation or exceeds the permitted use, you will need to obtain permission directly from the copyright holder. To view a copy of this license, visit http://creativecommons.org/licenses/by/4.0/. 


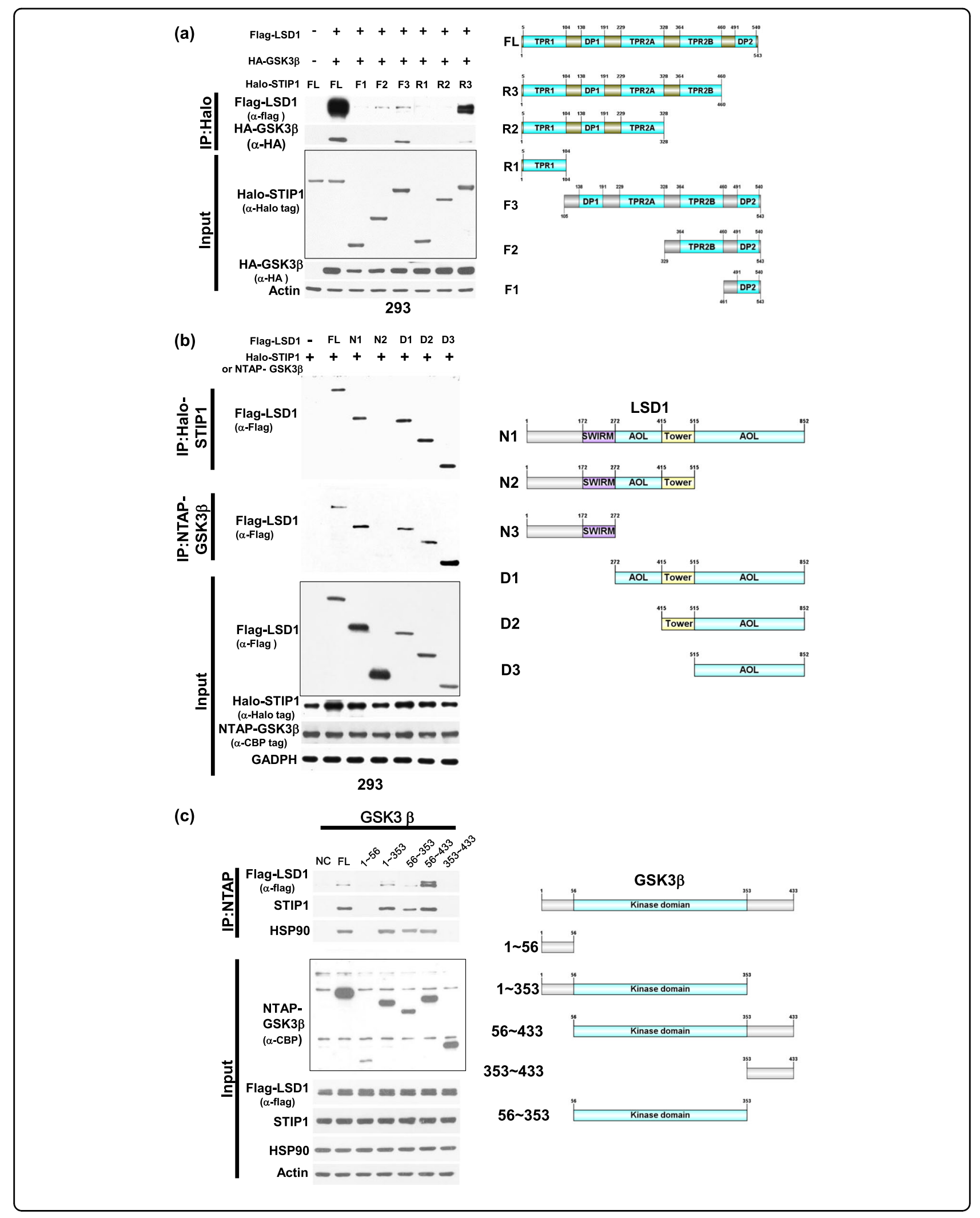



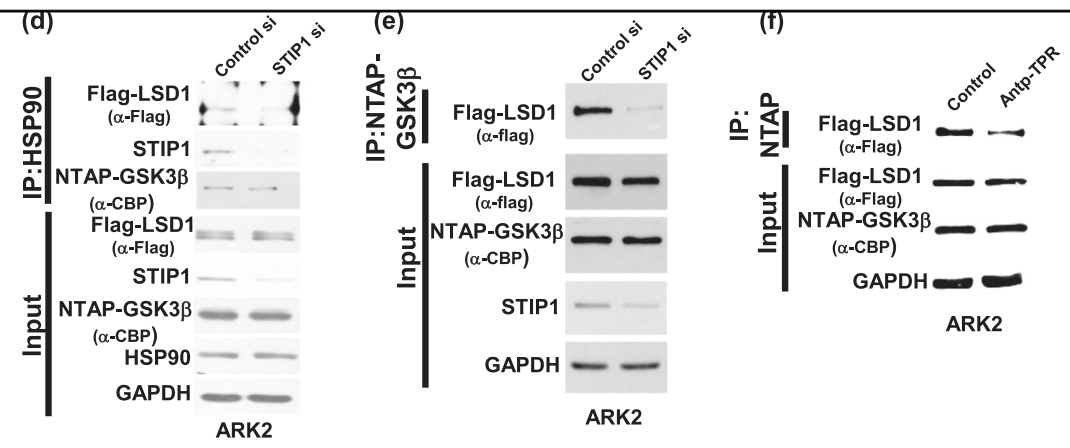

Fig. 1 STIP1 is required for the formation of complexes containing LSD1 and GSK3 $\beta$. a As far as STIP1 is concerned, we used the following Halo-tagged constructs: (1) the full-length (FL) protein, (2) N-terminal deleted halo-tag STIP1 constructs (F3: TPR1 deleted, F2: TPR1-DP1-TPR2A deleted and F1: TPR1-DP1-TPR2A-TPR2B deleted), and (3) C-terminal deleted halo-tag STIP1 constructs (R3: DP2 deleted, R2: TPR2B-DP2 deleted, and R1: DP1-TPR2A-TPR2B-DP2 deleted). The constructs were co-transfected with Flag-LSD1 or HA-GSK3 $\beta$ in 293 cells and subsequently purified with Halo-tag resin. The interactions between LSD1 and GSK3 $\beta$ were examined with Western blot. b, c 293 cells were co-transfected with (1) FL flag-LSD1, (2) its deleted N-terminal Flag-LSD1 constructs (D1: amino acid 272-852, D2: amino acid 415-852, and D3: amino acid 515-852), (3) its deleted Cterminal Flag-LSD1 constructs (N1: amino acid 1-515, D2: amino acid 1-272), and (4) FL Halo-STIP1 or NTAP-GSK3 $\beta$. After purification with a halotag resin (Halo-STIP1) or streptavidin beads (NTAP-GSK3ß), co-immunoprecipitated Flag-LSD1 constructs were analyzed with Western blot using an anti-flag tag antibody. $\mathbf{c}$ The identification of GSK3 $\beta$ domains involved in the interaction was performed by immunoprecipitation using a streptavidin resin to pull-down NTAP-GSK3 $\beta$ constructs. Full-length NTAP-GSK3 3 or its truncated constructs-including deleted N-terminal NTAP-GSK3 $\beta$ constructs (amino acid 56-433 and 353-433), deleted C-terminal NTAP- GSK3 $\beta$ constructs (amino acid 1-56 and 1-353) and a kinase domain construct (amino acid 56-353) were co-transfected with full-length Flag-LSD1 in 293 cells. Co-immunoprecipited HSP90, STIP1, and Flag-LSD1 were analyzed with Western blot using anti-HSP90, anti-STIP1 and anti-Flag antibodies, respectively. NTAP-GSK3 $\beta$ constructs were detected with an anticalmodulin binding peptide (CBP) antibody. d The endogenous HSP90 complex in ARK2 cells were immunoprecipitated with an anti-HSP90 antibody in presence of scrambled siRNA or STIP1 siRNA. The proteins interacting with HSP90 (i.e., STIP1, LSD1, and GSK3B) were identified with Western blot. e, f The interaction between Flag-LSD1 and NTAP-GSK3 $\beta$ in ARK2 cells was assayed by precipitation with streptavidin beads in presence of scrambled siRNA, STIP1 siRNA (e), or vehicle control (PBS) and Antp-TPR $(20 \mu \mathrm{M})(\mathbf{f})$. The STIP1, NTAP-GSK3 $\beta$, and Flag-LSD1 complexes were analyzed with Western blot

Histone lysine-specific demethylase 1 (LSD1; also known as KDM1A, Gene ID 23028)-a major epigenetic regulator-is capable of removing methyl groups from histone H3 lysine 4 (H3K4) or histone H3 lysine 9 $(\mathrm{H} 3 \mathrm{~K} 9)^{15}$. LSD1 is structurally characterized by the presence of three major domains, i.e., an N-terminal SWIRM domain, a central protruding tower domain, and a Cterminal amine oxidase like (AOL) domain ${ }^{16}$. Besides catalyzing histone demethylation, LSD1 is capable of interacting with other proteins involved in oncogenesis (including DNMT1 and p53) ${ }^{17}$. Importantly, it also acts as a prosurvival factor ${ }^{18}$ and is overexpressed in numerous cancers ${ }^{19-22}$. Several kinases are able to regulate the biological function of LSD1 through phosphorylation ${ }^{11,23}$. For example, protein kinase C $\alpha(\mathrm{PKC} \alpha)$-mediated LSD1 phosphorylation at serine 112 activates gene expression ${ }^{24}$ and promotes the acquisition of a metastatic phenotype in breast cancer ${ }^{23}$. Moreover, casein kinase 2 (CK2)-mediated LSD1 phosphorylation at serine 131 and serine 137 activates the DNA repair machinery ${ }^{25}$ and could serve as a target for the development of anticancer drugs.

Glycogen synthase kinase-3 beta (GSK3 $\beta$ ) - a serine/ threonine kinase involved in the regulation of multiple signaling pathways-recognizes substrates containing a short consensus phosphorylation $(\mathrm{S} / \mathrm{T}) \mathrm{XXX}(\mathrm{S} / \mathrm{T})$ motif $^{26,27}$. Although knockdown of GSK3 $\beta$ has been shown to suppress tumor cell growth and proliferation in some studies ${ }^{28,29}$, this effect is variable and might be context-dependent ${ }^{30,31}$. This phenomenon may at least in part be explained by ability of GSK3 $\beta$ to interact with different specific substrates.

Owing to their ability to tether different molecules into functional complexes, scaffold proteins have a key role in the regulation of different signaling pathways in tumorigenesis $^{32}$. In this regard, HSP90 is capable of forming complexes with LSD1 to regulate estrogen receptormediated transcription ${ }^{22}$ and may bind with both $\beta$ catenin and GSK3 $\beta$. Because the GSK3 $\beta$-mediated $\beta$ catenin phosphorylation is blocked by HSP90 inhibitors ${ }^{33}$, we reasoned that the STIP1-HSP90 complex could interact with LSD1 and GSK3 $\beta$ to regulate LSD1 function in human oncogenesis. In the current study, we demonstrate that the STIP1-HSP90 complex is involved in GSK3 $\beta$-mediated LSD1 phosphorylation by acting as scaffold that transfers LSD1 to GSK3 $\beta$. Our data ultimately provide novel mechanistic insights into the role of STIP1 in tumorigenesis. 


\section{Results}

STIP1 is capable of interacting with both LSD1 and GSK3 $\beta$ to form complexes

To investigate whether STIP1 was capable of interacting with both LSD1 and GSK3 $\beta$ in living cells, systematically truncated constructs of STIP $1^{5}$ were used to pull-down complexes. The deletion of TPR1 in F3/STIP1 and the deletion of TPR2B in R2/STIP1 (Fig. 1a) markedly decreased the capacity of STIP1 to bind LSD1. Moreover, the deletion of TPR2A in F2/STIP1 and the deletion of TPR2B in R2/STIP1 resulted in a diminished STIP1/ GSK3 $\beta$ interaction. Interestingly, deletion of the AOL domains in N2/LSD1 reduced both the LSD1/STIP1 and the LSD1/GSK3 $\beta$ interactions (Fig. 1b). Conversely, the Cterminal segment of AOL domain (D3/LSD1) in LSD1 was sufficient to allow binding to both STIP1 and GSK3 $\beta$ (Fig. 1b). Notably, the kinase domain of GSK3 $\beta$ (from amino acid 56 to amino acid 353) was required to ensure the interaction with both STIP1 and LSD1 (Fig. 1c). Taken together, these results suggest that STIP1 can form complexes with both LSD1 and GSK3 $\beta$. Specifically, the TPR1 and TPR2B domains of STIP1 are essential for mediating its interaction with LSD1, whereas its TPR2A and TPR2B domains are necessary for its binding to GSK3 $\beta$. The C-terminal AOL domain of LSD1 mediates the interaction of STIP1 with GSK3 $\beta$. Finally, the kinase domain of GSK3 $\beta$ is critical for interaction between STIP1 and LSD1. Of note, in all of these experiments, we cannot exclude the role of endogenous HSP90.

\section{STIP1 tethers both LSD1 and GSK3 $\beta$}

Knockdown of endogenous STIP1 inhibited the binding of LSD1 to both HSP90 (Fig. 1d) and GSK3 $\beta$ (Fig. 1e), although it did not affect the HSP90/GSK3 $\beta$ interaction (Fig. 1d). Antp-TPR - a peptide derived from the TPR2A domain of STIP1 - is capable of blocking the formation of the STIP1-HSP90 complex ${ }^{5,34}$. To investigate the role played by STIP1-HSP90 in mediating the interaction between LSD1 and GSK3 3 , cancer cells were treated with the Antp-TPR peptide ${ }^{34}$. The results showed that $20 \mu \mathrm{M}$ Antp-TPR peptide partially blocked the LSD1/GSK3 $\beta$ interaction (Fig. 1f), suggesting a role for the STIP1-HSP90 complex in tethering both LSD1 and GSK3 $\beta$.

\section{LSD1 is a substrate for GSK3 $\beta$-mediated phosphorylation}

Figure 2a shows the location of the predicted GSK3 $\beta$ phosphorylation motif (STTAS) along various LSD1 protein sequences. Pull-down experiments (performed with anti-phospho-serine) on lysates from cells cotransfected with LSD1 and constitutively active GSK3 $\beta$ (HA-GSK3 $\beta$ S9A) showed increased phospho-LSD1 protein levels (Fig. 2b). In an in vitro kinase assay, wild-type or double-mutant (S707A/S711A, which is unable to

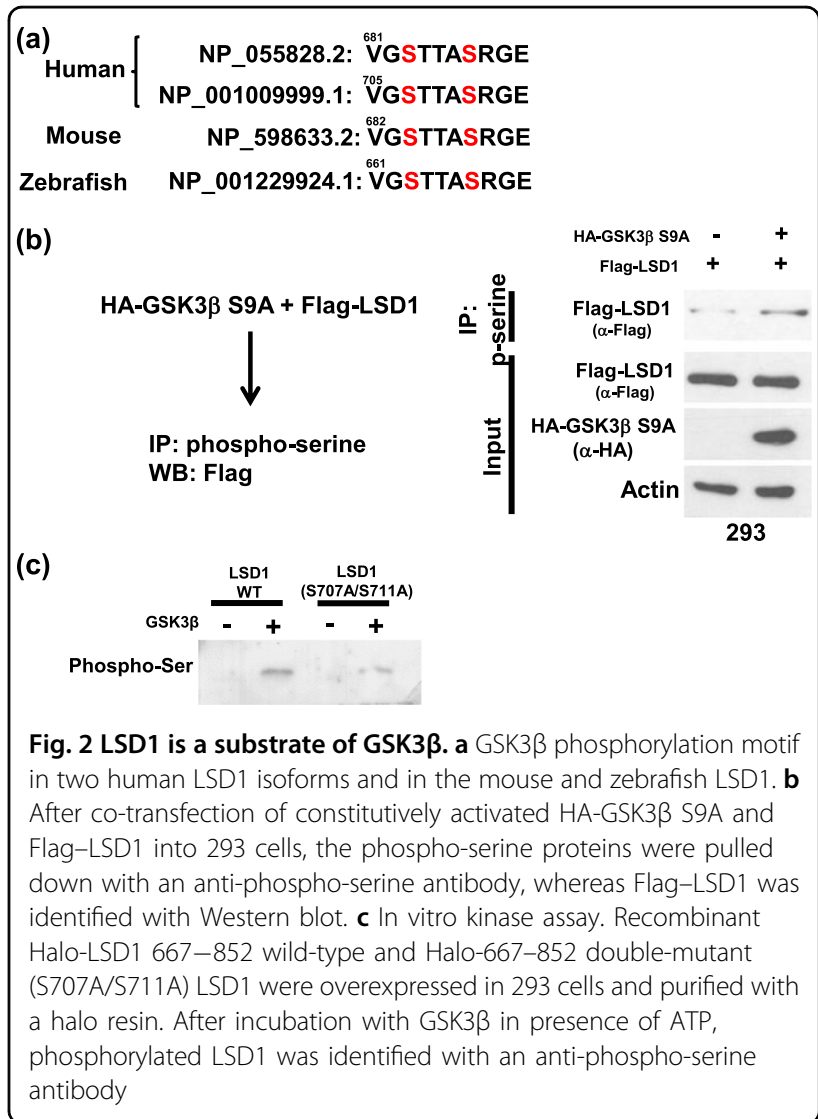

undergo effective GSK3 $\beta$-mediated phosphorylation) LSD1 were subsequently purified and incubated with GSK3 $\beta$ in presence of adenosine triphosphate (ATP). The results indicated that the double-mutant (S707A/S711A) LSD1 resulted in lower phospho-serine levels compared with wild-type LSD1 (Fig. 2c), suggesting that wild-type LSD1 can effectively undergo GSK3 $\beta$-mediated phosphorylation.

\section{GSK3 $\beta$-mediated LSD1 phosphorylation promotes LSD1 protein stability}

To investigate LSD1 function in relation to GSK3 $\beta$ mediated phosphorylation, we compared the protein stability of wild-type LSD1 versus double-mutant (S707A/ S711A) LSD1 when overexpressed in cancer cells in presence of cycloheximide. Protein levels of doublemutant (S707A/S711A) LSD1 (which is unable to undergo effective GSK3 $\beta$-mediated phosphorylation) were significantly decreased after exposure of cancer cells to cycloheximide for $2 \mathrm{~h}$ (Fig. 3a). As ubiquitinated proteins are efficiently degraded in the proteasome, we had to add a proteasome inhibitor MG132 to show the differential ubiquitinated levels. Ubiquitinated levels of the double-mutant (S707A/S711A) LSD1 were higher than that of the wild-type LSD1 (Fig. 3b). The protein amount 
(a)

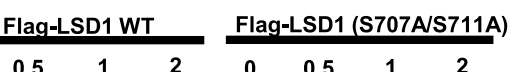

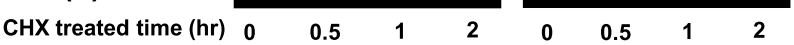<smiles>CCCCCCCC</smiles>

\section{SKOV3}

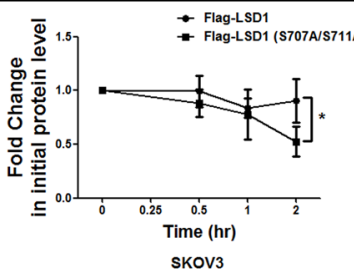

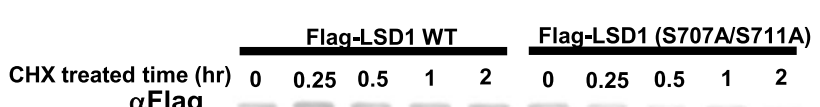

Actin $-\infty-\infty-\infty-\infty$

ARK2

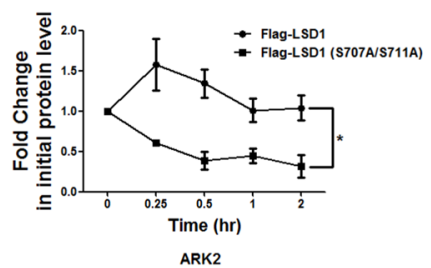

(b)
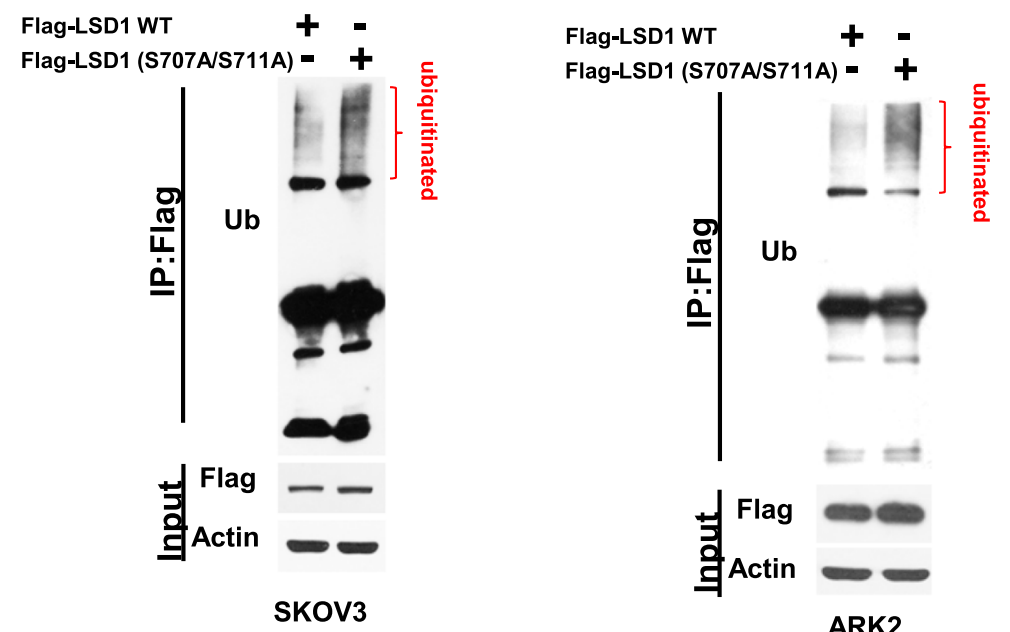

Ub

뜸
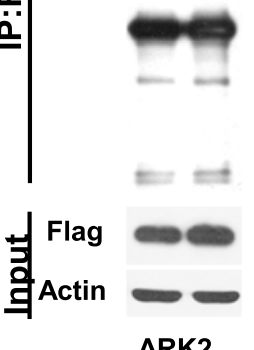

(c) Control MG132
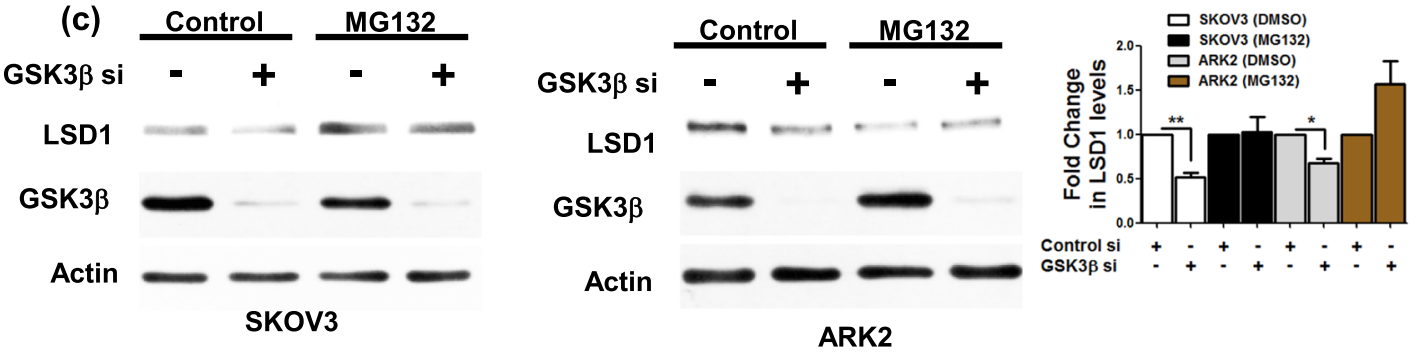

(d)

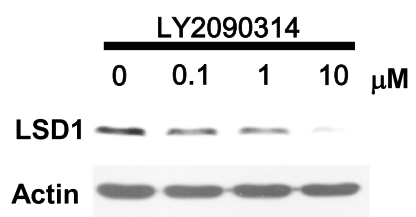

Mono-MethylHistone H3 (K4)

Mono-Methyl-

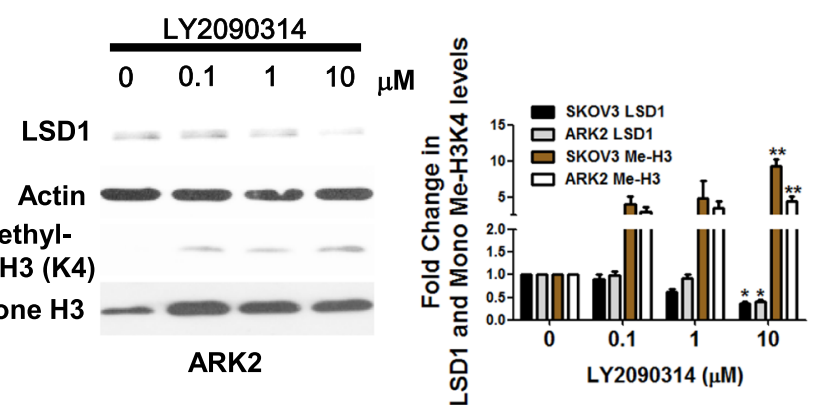




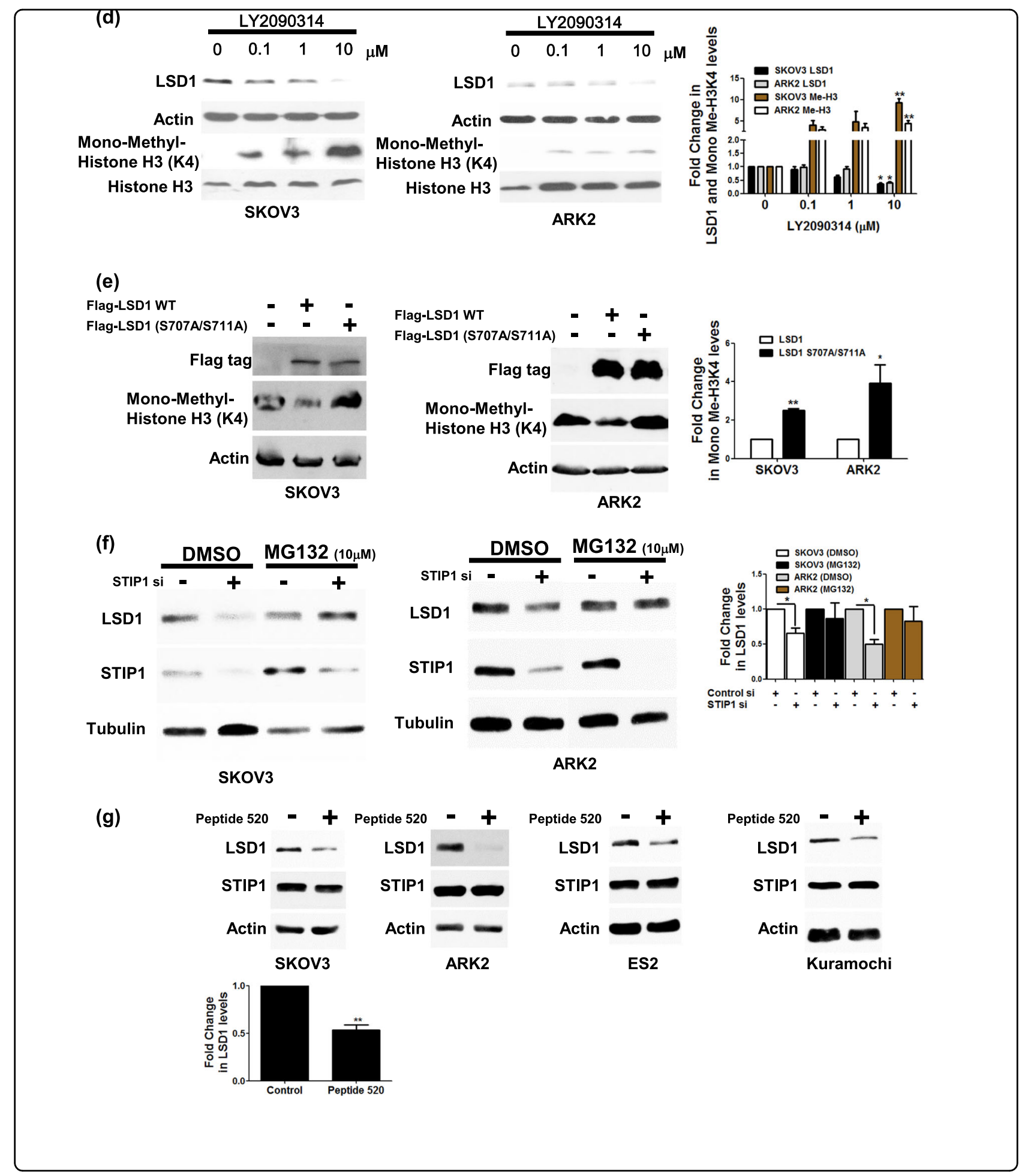

of LSD1 was decreased in GSK3 $\beta$-knocked down cancer cells, but such decrease could be inhibited by treatment with MG132 (Fig. 3c). When cells were exposed to the specific GSK3 $\beta$ inhibitor LY2090314, protein levels of LSD1 were reduced in a dose-dependent manner. In addition, histone $\mathrm{H} 3$ lysine 4 methylation (whose levels are reduced by LSD1 activity) were found to be increased (Fig. 3d). Finally, the demethylation capacity of doublemutant (S707A/S711A) LSD1 was absent when overexpressed in cancer cells (Fig. 3e). Taken together, these data suggest that GSK3 $\beta$-mediated LSD1 phosphorylation stabilizes LSD1 protein. 
Fig. 3 GSK3 $\beta$ maintains LSD1 stability. a Ovarian (SKOV3) and endometrial (ARK2) cancer cells were transfected with Flag-wild-type LSD1 or Flagdouble-mutant (S707A/S711A) LSD1. Overexpressed LSD1 protein levels were determined by Western blot with an anti-Flag antibody in presence of $25 \mu \mathrm{g} / \mathrm{ml}$ cycloheximide $(\mathrm{CHX})$ at the indicated time point. Actin levels were used to normalize the input proteins. b After treatment with $25 \mu \mathrm{M}$ MG132 for $6 \mathrm{~h}$, exogenous Flag-wild-type LSD1 or Flag-double-mutant (S707A/S711A) LSD1 in cancer cells (SKOV3 and ARK2) were immunoprecipitated with an anti-Flag antibody. Ubiquitin-conjugated, Flag-wild-type LSD1, or Flag-double-mutant (S707A/S711A) LSD1 were identified with Western blot using an anti-ubiquitin antibody. Protein lysates $(50 \mu \mathrm{g})$ were used as a loading control and probed with anti-Flag and anti-actin antibodies. c Cancer cells (SKOV3 and ARK2) were treated with MG132 (25 $\mu \mathrm{M})$ for $6 \mathrm{~h}$ either with or without GSK3 $\beta$ siRNA. Endogenous LSD1 and GSK3 $\beta$ protein levels were determined with Western blot. $\mathbf{d}$ SKOV3 and ARK2 cells were treated for $24 \mathrm{~h}$ with different concentrations of the GSK3 $\beta$ inhibitor LY2090314. Protein levels of LSD1, mono-methylated H3K4, total histone 3, and actin were determined with Western blot. e SKOV3 and ARK2 cells were transfected with Flag-wild-type LSD1 or Flag-double-mutant (S707A/S711A) LSD1. Protein levels of Flag-wild-type LSD1 or Flag-double-mutant (S707A/S711A) LSD1, mono-methylated histone H3K4, and actin were determined with Western blot. f After STIP1 siRNA transfection for $72 \mathrm{~h}$, SKOV3 and ARK2 cells were treated with MG132 $(25 \mu \mathrm{M})$ for $6 \mathrm{~h}$. Untreated cells served as controls. Protein levels of LSD1, STIP1, and tubulin were determined with Western blot. g Cancer cells (SKOV3, ARK2, ES2, and Kuramochi) were treated with peptide $520(10 \mu \mathrm{M})$ for $72 \mathrm{~h}$ in serum-free medium. Endogenous protein levels of LSD1, STIP1, and actin were determined with Western blot. Results shown were obtained from three independent experiments and are presented as mean \pm standard error (SE). ${ }^{*} P<0.05$ and ${ }^{* *} P<0.01$, Student's $t$-test

\section{The STIP1-HSP90 complex is required for LSD1 protein stability}

RNA silencing and the peptide $520^{5}$ were used to shed more light on the role played by the STIP1-HSP90 complex in LSD1 protein stability. Although LSD1 protein levels were decreased in STIP1-silenced cancer cells, the proteasome inhibitor MG132 restored its normal expression (Fig. 3f). For further confirmation, the peptide 520 was used to disrupt the interaction between STIP1 and $\mathrm{HSP}^{5}$. The results indicated that exposure of cancer cells to the peptide 520 reduced LSD1 expression (Fig. $3 g)$. Taken together, these data suggest that the STIP1-HSP90 complex is required for LSD1 protein stability.

\section{GSK3 $\beta$-mediated LSD1 phosphorylation drives its subcellular localization}

Wild-type Flag-LSD1 was found to be located in the nucleus. In contrast, approximately $10 \%$ of Flag-doublemutant (S707A/S711A) LSD1 was localized in both the cytoplasm and the nucleus (Fig. 4a). To shed more light on these findings, cell fractionation experiments were conducted. The results revealed that Flag-double-mutant (S707A/S711A) LSD1 protein levels were decreased in the nucleus, whereas they were found to be increased in the cytoplasm (Fig. 4b). The specific GSK3 $\beta$ inhibitor LY2090314 also caused the translocation of wild-type LSD1 from the nucleus to the cytoplasm (Fig. 4c, d). The major signal of LSD1 was locked in the nucleus by leptomycin B (right panel, Fig. 4c), and signal of LSD1 in the cytoplasm only appeared in the absence of leptomycin B (middle panel, Fig. 4c). Taken together, these findings indicate that GSK3 $\beta$-mediated LSD1 phosphorylation helps retention of LSD1 in the nucleus.

\section{GSK3 $\beta$-mediated LSD1 phosphorylation promotes cell proliferation}

Cells stably expressing Flag-LSD1 or Flag-doublemutant (S707A/S711A) LSD1 were used to investigate whether GSK3 $\beta$ phosphorylation might be involved in LSD1-mediated cell growth. The BrdU assay and Ki67 staining were used as markers of cell proliferation. Compared with Flag-LSD1, cells stably expressing Flagdouble-mutant (S707A/S711A) LSD1 showed both a decreased BrdU incorporation rate and a less prominent Ki67 staining (Fig. 5a, b). A reduced colony growth was observed in cells expressing Flag-double-mutant (S707A/ S711A) LSD1 (Fig. 5c). Taken together, these data suggest that GSK3 $\beta$-mediated LSD1 phosphorylation promotes cell proliferation.

\section{The LSD1 inhibitor SP2509 and the GSK3 $\beta$ inhibitor LY2090314 exert synergistic antitumor effects}

To investigate whether the combination of the LSD1 inhibitor SP2509 and the GSK3 $\beta$ inhibitor LY2090314 could exert synergistic antitumor effects, different concentrations of the two molecules were tested. SP2509 at a $10 \mu \mathrm{M}$ concentration caused death in $50 \%$ of SKOV3 cells, whereas a $1 \mu \mathrm{M}$ concentration was sufficient to cause ARK2 cell death in an identical amount. A 50\% cell death was observed for both cell lines when LY2090314 was used at a $10 \mu \mathrm{M}$ concentration (Fig. 5d). Combined treatment with both SP2509 and LY2090314 in both SKOV3 and ARK2 cells exerted synergistic cytotoxic effects, ultimately increasing the cell death rate to $75 \%$ (Fig. 5d). Levels of cell death-associated proteins (including cleaved caspase-3 and cleaved poly-(ADPribose)-polymerase [PARP]) were also increased when the two inhibitors were used in combination (Fig. 5e, f). As expected, histone $\mathrm{H} 3$ lysine 4 methylation was markedly increased upon LY2090314 treatment (Fig. 5e, f). The in vivo treatment with both LY2090314 and SP2509 inhibited tumor proliferation more effectively than 
(a)

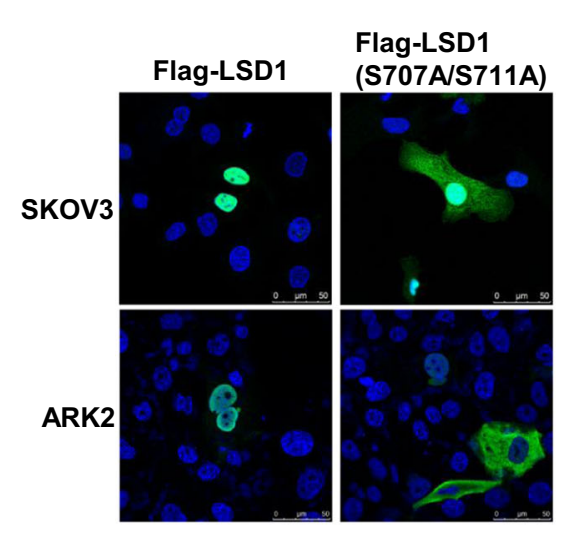

(b)
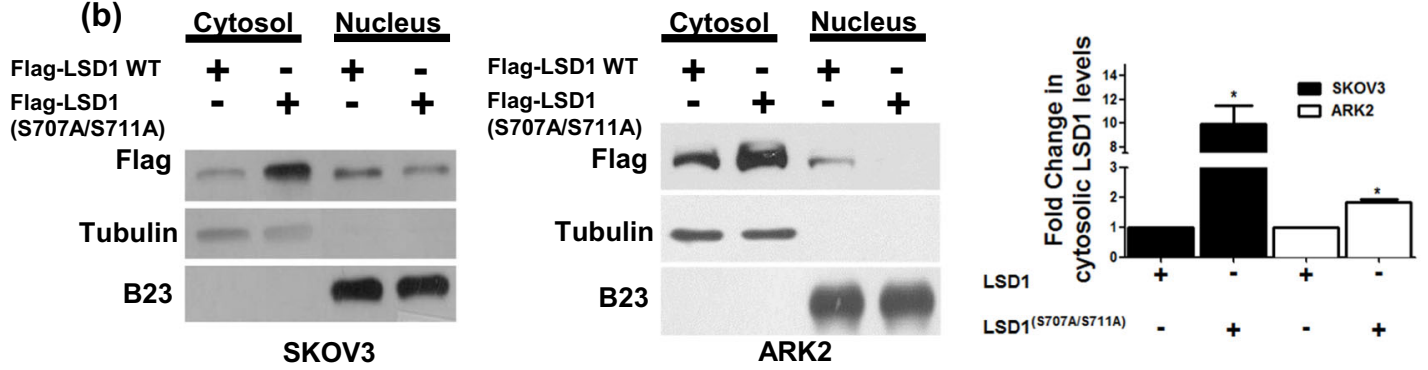

(c)

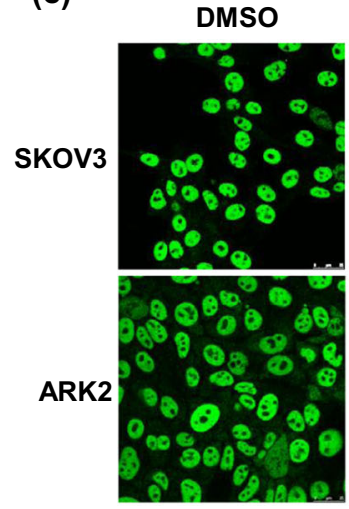

LY2090314

LY2090314+
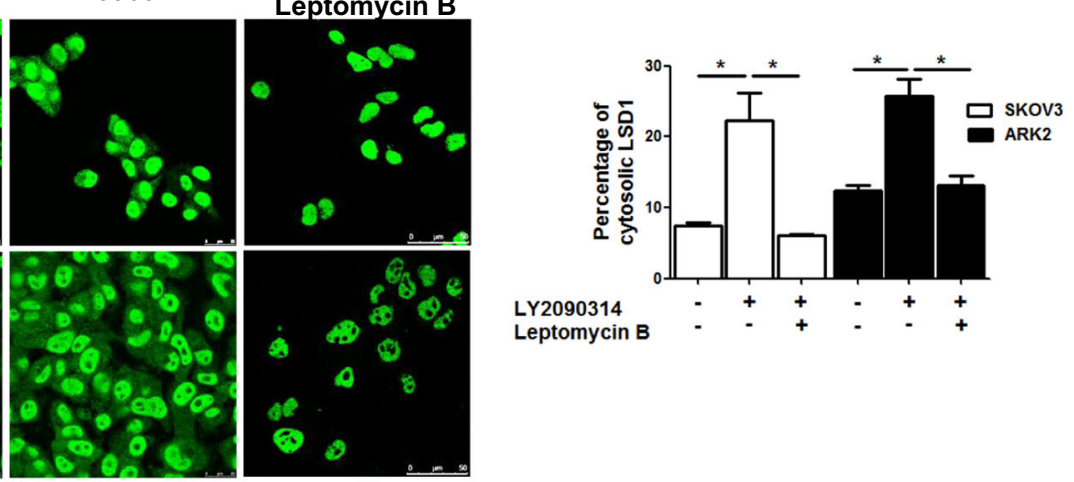

(d)
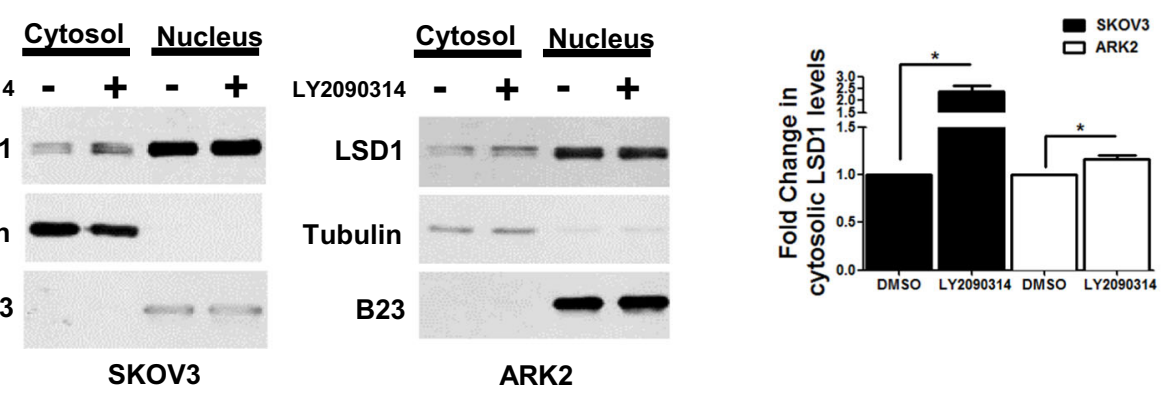

SKOV3

\section{ARK2}

Fig. 4 Phosphorylation of LSD1 alters its subcellular localization. a The subcellular localization of Flag-wild-type LSD1 or Flag-double-mutant (S707A/S711A) LSD1 (green) was investigated with confocal microscopy. b Nuclear and cytoplasmic fractions obtained from cancer cells (SKOV3 and ARK2) overexpressing Flag-wild-type LSD1 or Flag-double-mutant (S707A/S711A) LSD1 were analyzed with Western blot using anti-Flag, anti-tubulin (cytoplasmic marker), and anti-B23 (nuclear marker) antibodies, respectively. c Confocal microscopy image indicated the intracellular localization of

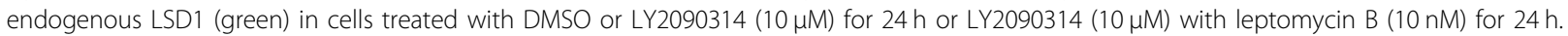
Cytosolic LSD1 were quantified with MetaMorph software. d SKOV3 and ARK2 cells were treated DMSO or LY2090314 (10 $\mu \mathrm{M})$ for $24 \mathrm{~h}$. Protein levels of the nuclear or cytoplasmic fractions of LSD1, tubulin, and B23 were determined with Western blot. Results shown were obtained from three independent experiments and presented as mean \pm standard error $(\mathrm{SE}) .{ }^{*} P<0.05$, Student's $t$-test 
(a)

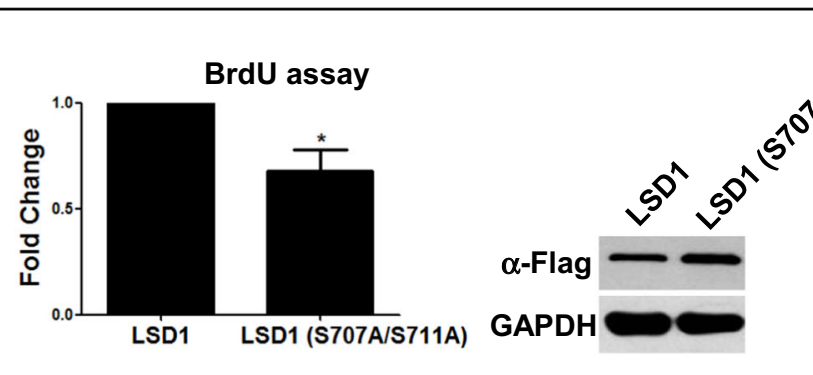

(b)

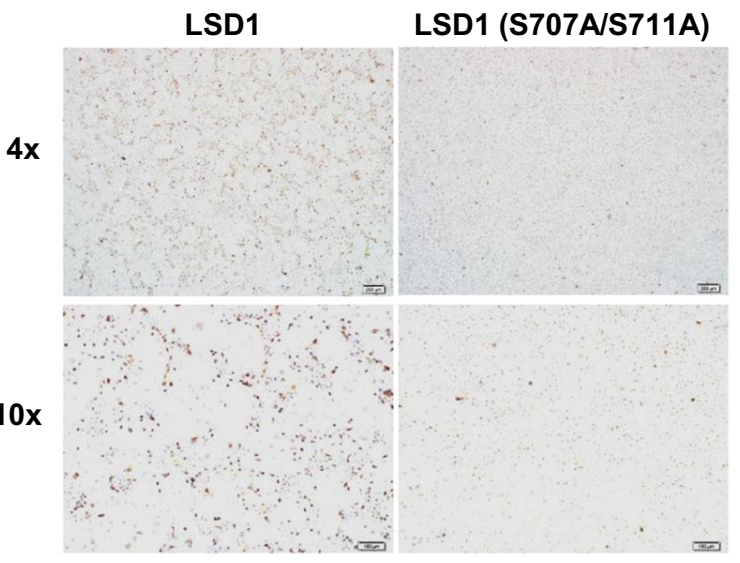

(c)

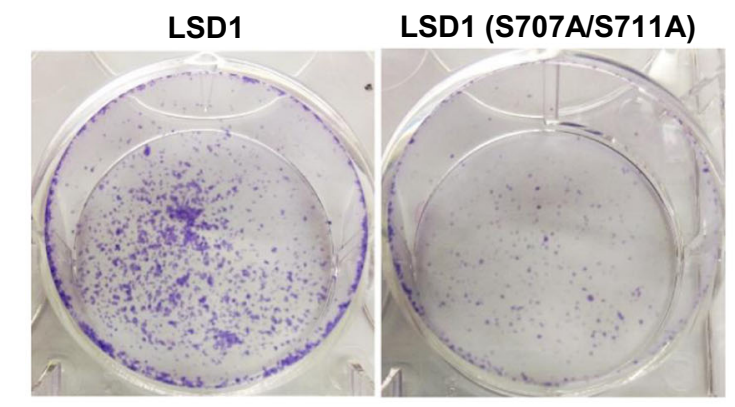

(d)

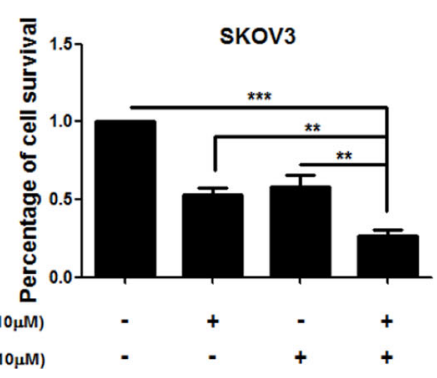

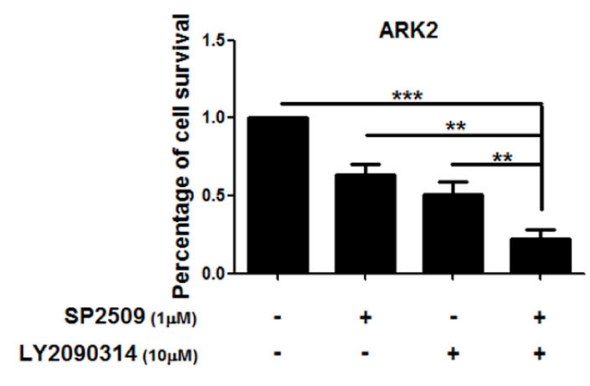

LY2090314 or SP2509 alone (Fig. 5g). Taken together, these results indicate that LSD1 and GSK3 $\beta$ inhibitors can exert synergistic antitumor effects when used in combination.
Immunohistochemical co-expression of STIP1, LSD1, and GSK3 $\beta$ in human cancer tissues

A proximity ligation assay (PLA) was performed to identify the interactions between LSD1 and GSK3 $\beta$ in formalin-fixed, paraffin-embedded endometrial cancer specimens. The results revealed that the interaction between LSD1 and GSK3 $\beta$ mainly occurred in the nucleus 

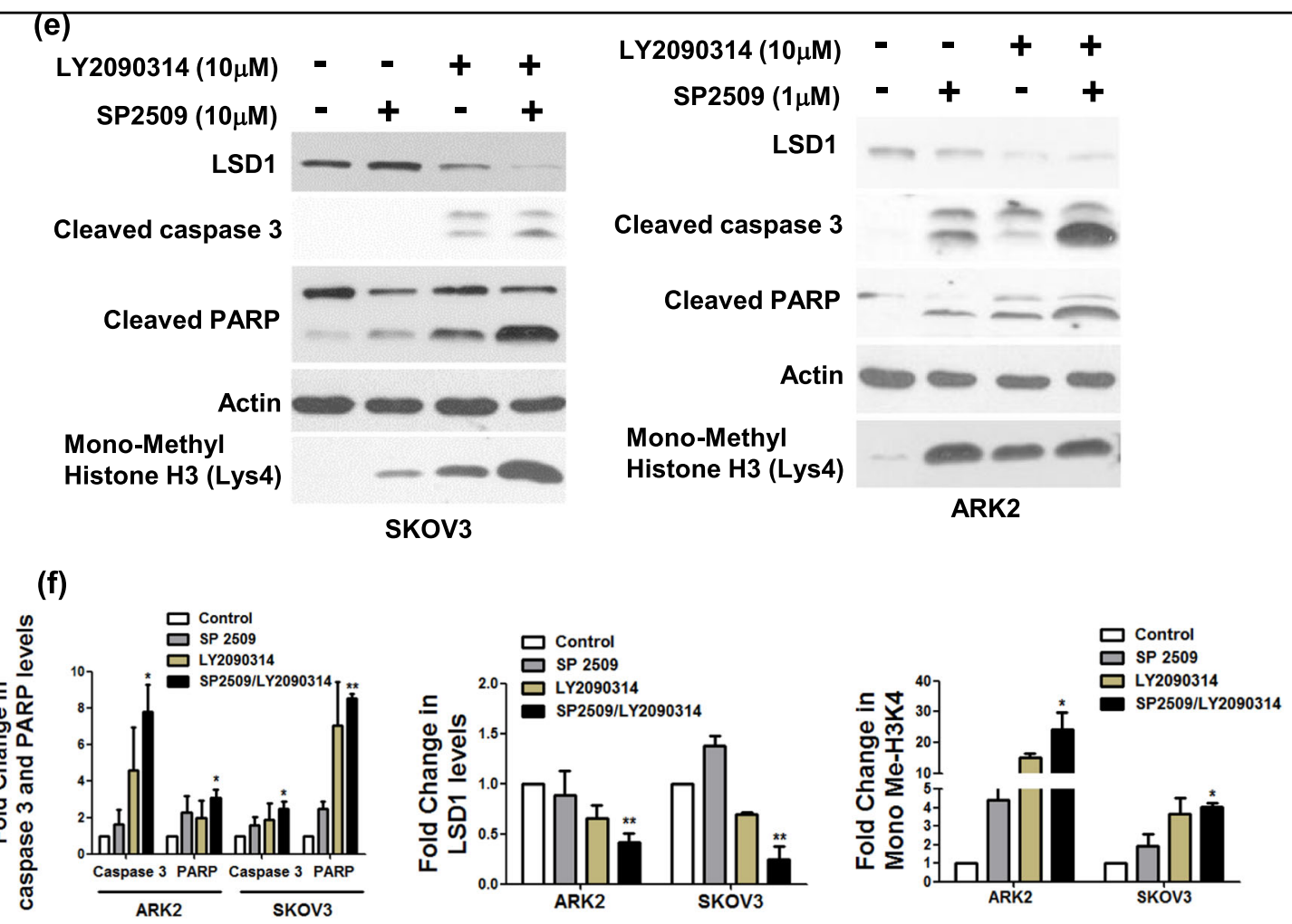

(g)
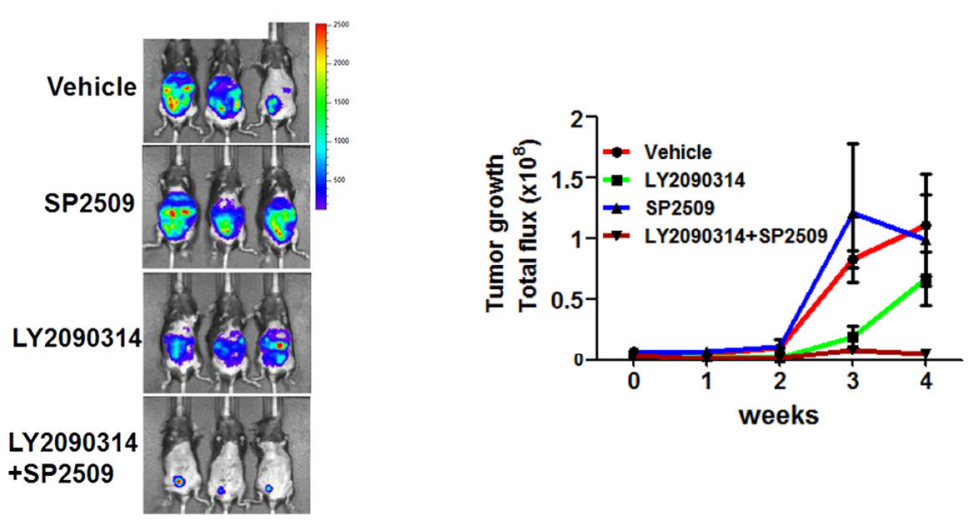

Fig. 5 The combination of the LSD1 inhibitor SP2509 and the GSK3 $\beta$ inhibitor LY2090314 exerts synergistic antitumor effects. a BrdU proliferation assay, b Ki67 protein immunostaining, and c colony formation assay in ARK2 cells (1000 cells cultured in 1\% FBS medium in 6-well plate) stably expressing Flag-wild-type LSD1 or Flag-double-mutant (S707A/S711A) LSD1. d SKOV3 and ARK2 cells were treated with the reported concentrations of SP2509, LY2090314, or a combination of SP2509 and LY2090314 for $72 \mathrm{~h}$. Cell survival was determined with the MTT assay. e Exposure of SKOV3 and ARK2 cells to a combination of SP2509 and LY2090314 for $72 \mathrm{~h}$ increased apoptosis (as reflected by higher levels of cleaved caspase-3 and cleaved PARP quantified by Western blot). LSD1 activity was assessed by measuring protein levels of mono-methylated histone H3K4. Actin levels were used to normalize input proteins. $\mathbf{f}$ Quantified results from e were obtained from three independent experiments and are presented as mean \pm standard error (SE). ${ }^{*} P<0.05,{ }^{* *} P<0.01,{ }^{* * *} P<0.001$, Student's $t$-test. $\mathbf{g}$ Mosec/Luc cells $\left(1 \times 10^{6}\right)$ were intraperitoneally injected into C57BL/6 mice. One week later, mice were injected with vehicle alone, LY2090314 (10 mg/kg), SP2509 (10 mg/kg), or both twice a week. Tumor growth was measured on a weekly basis after treatment was started. Ascites were detected in mice treated with vehicle alone or SP2509. The mice were then analyzed with the IVIS Spectrum in vivo imaging system on a weekly basis. Data are expressed as means \pm standard error

(Fig. 6a). An endometrial cancer tissues with high expression of GSK3 $\beta$ exhibited higher levels of LSD1 (upper panels of Fig. 6b), whereas the GSK3 3 -lowly expressing one had lower levels of LSD1 (lower panels of Fig. 6b). Positive correlations between LSD1 and GSK3 $\beta$ expression were also identified in ovarian (Fig. 6c, left panel, $\mathrm{r}=0.39, P<0.05$ ) and endometrial cancer (Fig. 6c, right panel, $r=0.4, P<0.0001)$ specimens. A STIP1 highly expressing endometrial cancer tissues exhibited higher levels of LSD1 (upper panels of Fig. 6d), whereas a STIP1 


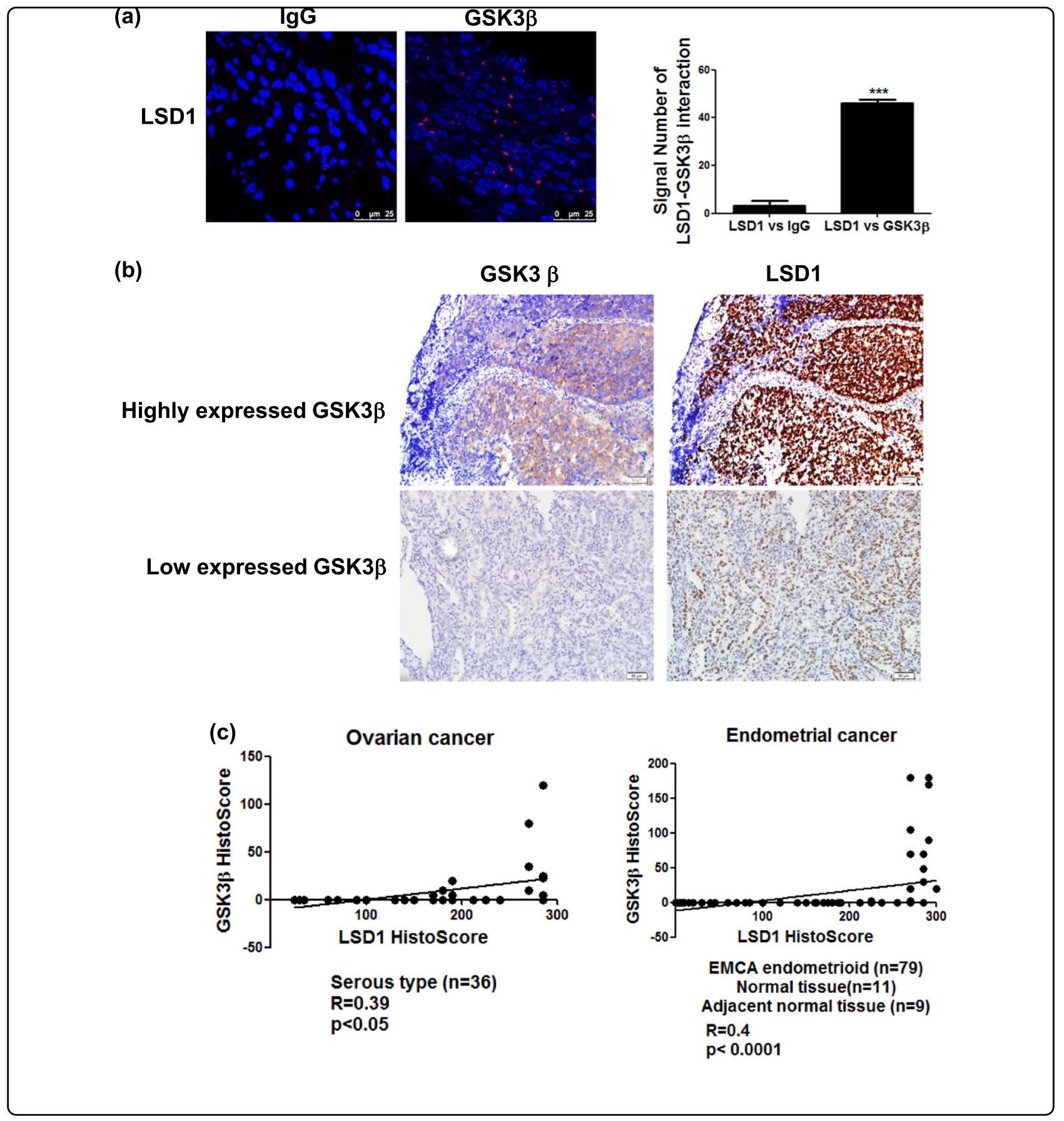

lowly expressing one had lower levels of LSD1 (lower panel of Fig. 6d). The immunohistochemical expression of STIP1 and LSD1 showed positive associations in both ovarian (Fig. 6e, left panel, $r=0.59, p<0.001$ ) and endometrial cancer (Fig. 6e, right panel, $r=0.59, p<0.0001$ ) tissues. Taken together, these preliminary data suggest that the interactions between STIP1, LSD1, and GSK3 $\beta$ observed in vitro do also occur in vivo.

\section{Discussion}

Herein, we unveiled the existence of a complex molecular interplay between STIP1, LSD1, and GSK3 $\beta$ (Fig. $7 \mathrm{a})$, that ultimately provides new mechanistic evidences on the role played by STIP1 in human tumorigenesis. First in the literature, our findings show that the STIP1-HSP90 complex acts as a scaffold to bring LSD1 and GSK3 $\beta$ together, thereby promoting GSK3 $\beta$-mediated LSD1 phosphorylation (Fig. 7b). Specifically, experiments with systematically truncated constructs of STIP1 revealed that 


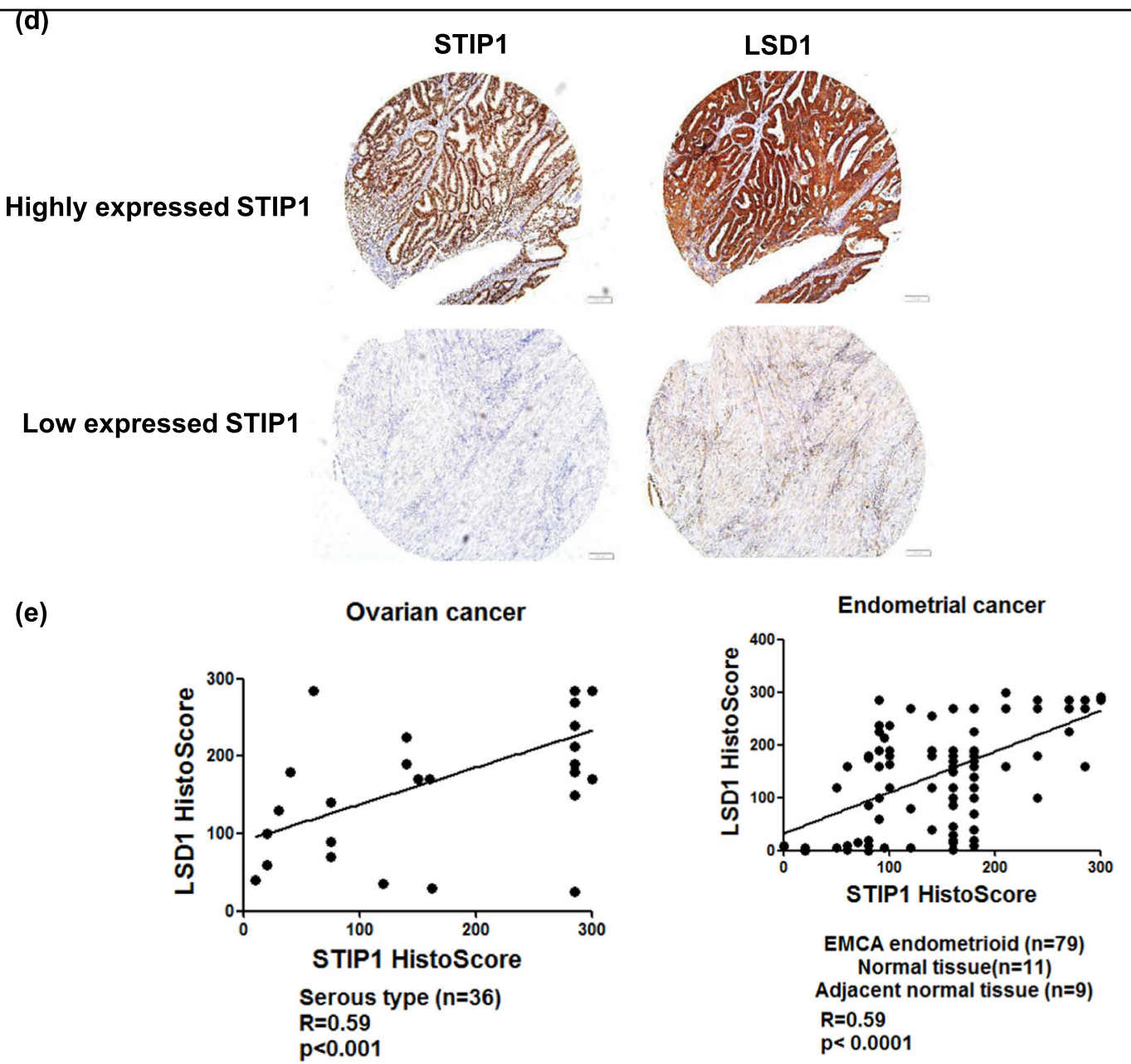

Fig. 6 LSD1 and GSK3 $\beta$ are co-expressed in human cancer specimens. a A proximity ligation assay showed an interaction between LSD1 and GSK3 $\beta$ in ovarian cancer specimens. Anti-STIP1 and Anti-LSD1 antibodies were used for staining, whereas an IgG served as a negative control. The signals were counted with ImageJ (https://imagej.nih.gov/ij/) (right panel). ${ }^{* *} P<0.001$, Student's t-test. $\mathbf{b}$ The immunohistochemical expression of LSD1 and GSK3 $\beta$ in endometrial cancer tissues was investigated. Endometrial cancers with high and low GSK3 $\beta$ immunohistochemical expression are shown in the upper and lower panels, respectively. $\mathbf{c}$ A histoscore was used to analyze LSD1 and GSK3 $\beta$ immunostaining in ovarian cancer ( $n=36$ ) and endometrial tissue array $(n=99)$. $\mathbf{d}$ Immunohistochemical staining of STIP1 and LSD1 was performed in an endometrial cancer tissue array. Endometrial cancer tissues with high and low STIP1 immunohistochemical expression are shown in the upper and lower panels, respectively. e The correlation between STIP1 and LSD1 expression in ovarian cancer $(n=36)$ and endometrial tissue array $(n=99)$ was analyzed with a histoscore

its TPR1 domain interacts with the C-terminal AOL domain of LSD1, whereas its TPR2A and TPR2B domains are capable of binding with the GSK3 $\beta$ kinase domain (Figs. 1 and 7a). Intriguingly, LSD1 and GSK3 $\beta$ were unable to form a complex in the absence of STIP1 (Fig. $1 \mathrm{~d}-\mathrm{f}$ ). We also demonstrated that GSK3 $\beta$-mediated LSD1 phosphorylation resulted in an increased LSD1 protein stability, associated with its nuclear expression and an effective demethylase activity. It has been previously reported that GSK3 $\beta$ phosphorylates and stabilizes LSD1 through the binding with the USP22 deubiquitinase ${ }^{35}$. Our results confirm and expand published data on the key role played by GSK3 $\beta$-mediated LSD1 phosphorylation at specific sites in promoting its stability.
Upregulation of STIP1 in various cancers ${ }^{7-9,11,12,14,36-38}$ is recently found to be regulated by both RAS activation and p53 inhibition ${ }^{39}$. Nuclear HSP90 chaperone complexes are involved in transcriptional regulation in nucleus ${ }^{40}$. HSP90 and its co-chaperones can form a complex with transcription factors and control gene expression through chromatin remodeling, histone modification or RNA polymerase II regulation ${ }^{40}$. However, it is unclear how HSP90 be translocated into the nucleus in the absence of nucleus localization sequence (NLS) ${ }^{41,42}$. HSP90 may interact with other proteins along with NLS that translocate into the nucleus ${ }^{41,42}$. In contrast, the mechanisms of STIP1 translocation are documented. Cytoplasmic STIP1 is promoted by Cdc2 kinase 


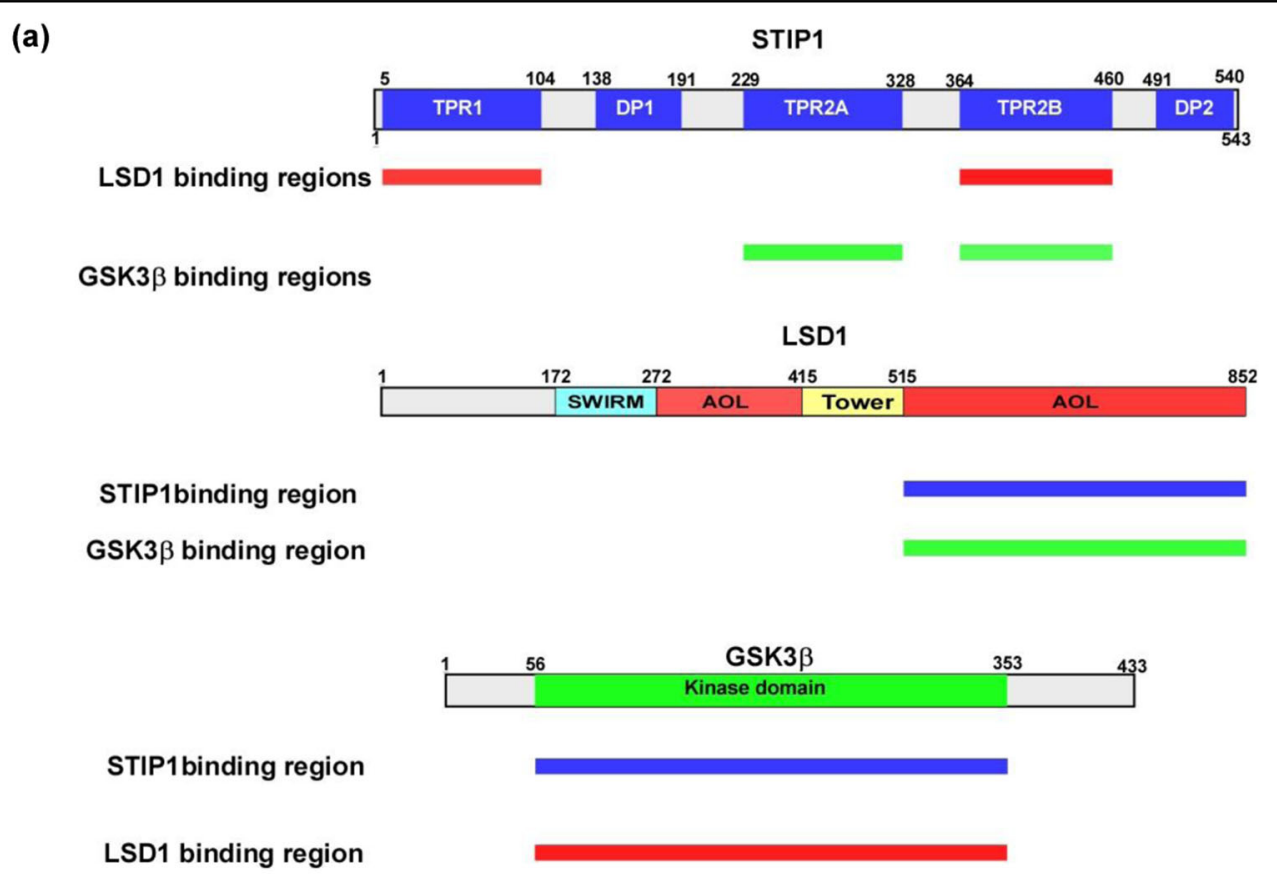

(b)

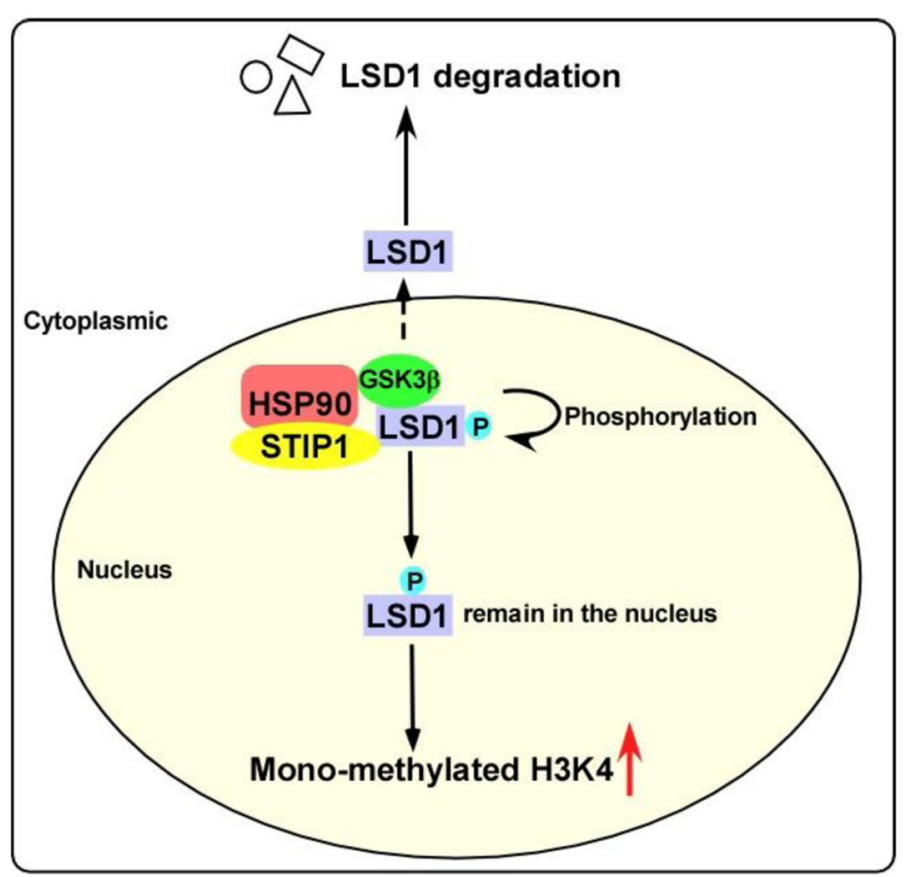

Fig. 7 Schematic representation of the role played by the STIP1-HSP90 complex in GSK3 $\beta$-mediated LSD1 phosphorylation. a Summary of the interactions between STIP1, LSD1, and GSK3 3 . $\mathbf{b}$ The STIP1-HSP90 complex acts as a scaffold promoting GSK3ß-mediated LSD1 phosphorylation. When GSK3 $\beta$-mediated LSD1 phosphorylation is inhibited, LSD1 translocates from the nucleus into the cytoplasm — where it undergoes degradation

phosphorylation, whereas the translocation of STIP1 is freely interacting with HSP90 in cytoplasm and controlled by Casein kinase II (CK2) phosphorylation ${ }^{43,44}$. STIP1 can also interact with Protein Inhibitor of Activated STAT1 (PIAS1) for nuclear retention ${ }^{45}$. As far as the key role of STIP1 as a scaffold protein is concerned, our data suggest that knockdown of endogenous STIP1 decreased both the LSD1/HSP90 interaction (Fig. 1d) and LSD1 protein levels (Fig. 3f). Interestingly, STIP1 gene silencing via siRNA or the use of a specific peptide disrupting the STIP1-HSP90 complex also blocked the interaction between LSD1 and GSK3 $\beta$ (Figs. 1e, f). In light of these findings, we 
hypothesize that HSP90-GSK3 $\beta$ complex translocates into the nucleus through NLS in GSK3 $\beta$ and that STIP1 may translocate by CK II phosphorylation, interact with LSD1 in the nucleus and subsequently promote its transfer to the HSP90-GSK3 $\beta$ complex, ultimately resulting in both appropriate LSD1 folding and subsequent phosphorylation.

Besides promoting protein stability, our results revealed that GSK3 $\beta$-mediated LSD1 phosphorylation was capable of regulating LSD1 cellular localization and demethylating functions. In particular, LSD1 was translocated from the nucleus to the cytoplasm in presence of a GSK3 $\beta$ inhibitor (Fig. 4c, d). Similar findings were observed in cancer cells overexpressing double-mutant (S707A/S711A) LSD1 (Fig. 4a, b). Notably, demethylase activity-which governs histone $\mathrm{H} 3$ lysine 4 methylation levels-was decreased by the exposure to a GSK3 $\beta$ inhibitor even at low concentrations (Fig. 3d). Double-mutant (S707A/S711A) LSD1 similarly increased histone H3 lysine 4 methylation levels. We speculate that GSK3 $\beta$-mediated phosphorylation maintains the nuclear localization of LSD1 and regulates its demethylase activity. In support of our hypothesis, the pharmacological inhibition of GSK3 $\beta$ promoted the following events: (1) translocation of LSD1 from the nucleus to the cytoplasm, (2) loss of its demethylase activity, and (3) its ultimate degradation.

The molecular chaperone HSP90 utilizes ATP as an energy source for recruiting a variety of client proteins involved in different signaling pathways ${ }^{32}$. Specific HSP90 inhibitors promote the degradation of HSP90 target proteins via the ubiquitin-proteasome pathway. We have previously shown that HSP90 inhibitors are capable of regulating JAK2 kinase stability ${ }^{5}$. Here, we demonstrate that HSP90 may interact with GSK3 $\beta$ to maintain its stability. Published data also suggest that GSK3 $\beta$ is degraded and its kinase activity is abrogated by HSP90 inhibitors ${ }^{33,46}$. Interestingly, an in vitro study revealed that GSK3 $\beta$ can phosphorylate HSP90 and stimulate its binding to STIP1 in cells characterized by a high proliferative potential ${ }^{47}$. Taken together, there is ample evidence that GSK3 $\beta$ is able to interact and phosphorylate HSP90. Upon phosphorylation, HSP90 acquires the capacity of binding to the STIP1-LSD1 complex, ultimately promoting the translocation of LSD1 to GSK3 $\beta$.

Interest in the antiproliferative potential of LSD1 and GSK3 $\beta$ inhibitors has recently gained momentum. SP2509 is a highly potent polyamine-based, reversible, and specific inhibitor of LSD1 that acts as a non-MAO-A and non-MAO-B inactivator ${ }^{48}$. SP2509 has been shown to inhibit tumor cell proliferation in solid malignancies (e.g., Ewing sarcoma, colorectal, breast, and endometrial can-

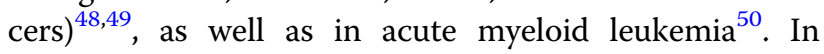
general, LSD1 inhibitors block its demethylase activity and activate target genes by restoring histone $\mathrm{H} 3$ lysine 4 methylation $^{51}$. As far as GSK3 $\beta$ inhibitors are concerned, LY2090314 is currently under investigation in a phase II trial of refractory/recurrent acute myeloid leukemia (clinicaltrials.gov identifier NCT01214603). Interestingly, we show here that LSD1 and GSK3 $\beta$ inhibitors used in combination were able to increase both cell death rates and levels of cell death-related proteins (i.e., cleaved caspase- 3 and cleaved PARP; Fig. 5d, e) compared with their use as monotherapy. This observation-coupled with the positive correlation between LSD1 and GSK3 $\beta$ immunohistochemical expression in human cancer specimens-may prompt further preclinical studies on the combined used of LSD1 and GSK3 $\beta$ inhibitors.

In summary, our current data provide mechanistic insights into the role of STIP1 in human tumorigenesis by showing that it serves as a scaffold for GSK3 $\beta$-mediated LSD1 phosphorylation. The combination of LSD1 and GSK3 $\beta$ inhibitors may exert synergistic antitumor effects and deserves further scrutiny in preclinical studies.

\section{Materials and methods \\ Culture, treatment, and transfection of cell lines}

Human ovarian cancer cells SKOV3, ES2, and 293 were obtained from the American Type Culture Collection (Manassas, VA, USA). Human ovarian cancer cells Kuramochi cells were purchased from the Japanese Collection of Research Bioresources Cell Bank (Osaka, Japan). The human endometrial cancer cell line ARK2 was kindly provided by Dr. Alessandro D. Santin (Yale School of Medicine, New Haven, CT, USA). Mouse ovarian surface epithelial cancer cell line (Mosec/Luc) was a gift from Dr. Chi-Long Chang (Institute of Biomedical Sciences, Mackay Medical College, Taiwan). SKOV3 and 293 cells were cultured in DMEM/F12 $2^{5,52}$, whereas ARK2, Kuramochi and Mosec/Luc cells were maintained in RPMI medium. In pharmacological experiments, cells were pretreated with the proteasome inhibitor MG132 $(10 \mu \mathrm{M}$ concentration; Sigma, St. Louis, MO, USA), the protein synthesis inhibitor cycloheximide $(25 \mu \mathrm{g} / \mathrm{ml}$ concentration, Sigma), the LSD1 inhibitor SP2509 (working concentration as indicated in figures; Selleck Chemicals, Houston, TX, USA), the GSK3 $\beta$ inhibitor LY2090314 (working concentration as indicated in figures; Selleck Chemicals), leptomycin B (10 nM in working concentration, Cell signaling, Danvers, MA), Antp-TPR ${ }^{34}(20 \mu \mathrm{M}$ working concentration; sequence: RQIKIWFQNRRMKWKKKAYARIGNSYFK; GeneDireX, Las Vegas City, NE, USA), and peptide $520^{5}(10 \mu \mathrm{M}$ working concentration; sequence: (D-Arginine) ${ }_{8}$-EHLKNPVIAQKIQKLMDVGLIAIR; Kelowna International Scientific, Taipei, Taiwan). To generate stably expressed wild-type LSD1 or LSD1 S707A/S711A cells, ARK2 cells were transfected with pLAS5w.PeGFP-I2-Puro-LSD1 or pLAS5w.PeGFP-I2-Puro-LSD1 S707A/S711A and treated 
with $5 \mu \mathrm{g} / \mathrm{ml}$ puromycin (Invitrogen, Carlsbad, CA, USA) at $48 \mathrm{~h}$ after transfection. One month later, the individual clones were selected and assayed for the LSD1 expression levels. siRNA and DNA transfection in ARK2 and SKOV3 were performed as previously described ${ }^{5,53}$.

\section{DNA construction}

Full-length and truncated LSD1 constructs were generated as described previously ${ }^{54}$. HA- GSK3 $\beta$ was a gift from Dr. Chi-Neu Tsai (Chang-Gung University, Taoyuan, Taiwan).The pNTAP-GSK3 $\beta$ deletion constructs were amplified and cloned into pNATP vector using an In-Fusion HD cloning kit (Clontech, Mountain View, CA, USA). The double-mutant (S707A/S711A) LSD1 and HA-GSK3 $\beta$ S9A were generated by overlapping PCR with a Q5 Site-Directed Mutagenesis Kit (New England Biolabs) according to the manufacturer's protocols. To construct the expression vector for the stably expression in cancer cells, the PCR products were amplified from Flag-LSD1 and Flag-LSD1 S707A/S711A and cloned into pLAS5w.PeGFP-I2-Puro (RNAi core laboratory, Sinica, Taiwan) with In-Fusion HD cloning kit (Clontech, Mountain View, CA, USA) according to the manufacturer's protocols. The primers used in DNA constructs are shown in Supplementary Table 1. The procedure was confirmed by DNA sequencing.

\section{Western blot analysis}

Western blot were performed as described previously ${ }^{5,54}$. All of the antibodies used for the experiments were obtained from commercial sources, as follows: LSD1, mono-methylated histone 3 lysine 4, total histone 3, and GSK3 $\beta$ were from Cell Signaling Technology (Danvers, MA, USA); calmodulin binding peptide tag (CBP) was from Millipore (Billerica, MA, USA); halo tag was from Promega (Madison, WI, USA); actin and STIP1 were from Santa Cruz Biotechnology (Santa Cruz, CA, USA). All corresponding horseradish peroxidase-conjugated antibodies were obtained from Santa Cruz Biotechnology. Enhanced chemiluminescence reagents were from Millipore. The signal intensity of autoradiograms was quantified using the ImageJ software (https://imagej.nih.gov/ij/) after normalization with the corresponding actin signal intensity.

\section{Cell fractionation}

After trypsinization and washing with cold PBS, cells were re-suspended in hypotonic buffer $(20 \mathrm{mM}$ Tris- $\mathrm{HCl}$, $\mathrm{pH}$ 7.4, $10 \mathrm{mM} \mathrm{NaCl}, 3 \mathrm{mM} \mathrm{MgCl} 2,10 \% \mathrm{NP}-40)$ and the supernatant containing the cytoplasm fraction was collected by centrifugation. The leftover nuclear pellets were lysed in cell extraction buffer $(100 \mathrm{mM}$ Tris- $\mathrm{HCl}, \mathrm{pH} 7.4$, $2 \mathrm{mM} \mathrm{Na}_{3} \mathrm{VO}_{4}, 100 \mathrm{mM} \mathrm{NaCl}, 1 \%$ triton $\mathrm{X}-100,1 \mathrm{mM}$
EDTA, 10\% glycerol, 1 mM EGTA, 0.1\% SDS, $1 \mathrm{mM} \mathrm{NaF,}$ $0.5 \%$ deoxycholate, and $20 \mathrm{mM} \mathrm{Na}_{4} \mathrm{P}_{2} \mathrm{O}_{7}$ ).

\section{Immunoprecipitation}

Cell lysates were prepared with Cell lysis buffer $(20 \mathrm{mM}$ Tris-Cl pH 7.4, $25 \mathrm{mM} \mathrm{NaCl}$ and $0.1 \%$ NP-40) with the cocktails of phosphatase inhibitors $(50 \mu \mathrm{g} / \mathrm{ml}$ Sodium Fluoride, $0.2 \mathrm{mg} / \mathrm{ml}$ Sodium Orthovanadate, $0.3 \mathrm{mg} / \mathrm{ml}$ Sodium Molybdate, $1.2 \mathrm{mg} / \mathrm{ml}$ Sodium Tartrate, $0.15 \mathrm{mg} /$ $\mathrm{ml}$ Imidazole, $1 \mu \mathrm{g} / \mathrm{ml}$ Cantharidin, $7.5 \mu \mathrm{g} / \mathrm{ml}(-)-p$-Bromotetramisole, $5 \mathrm{ng} / \mathrm{ml}$ Microcystin LR; Bionovas biotechnology, Toronto, Canada) and proteinase inhibitors $(25 \mu \mathrm{g} / \mathrm{ml}$ AEBSF, $2 \mu \mathrm{g} / \mathrm{ml}$ Aprotinin, $0.3 \mu \mathrm{g} / \mathrm{ml}$ Bestatin, $0.4 \mu \mathrm{g} / \mathrm{ml} \mathrm{E}-64,1 \mu \mathrm{g} / \mathrm{ml}$ Leupeptin, $1 \mu \mathrm{g} / \mathrm{ml}$ Pepstatin A, $10 \mu \mathrm{g} / \mathrm{ml}$ Benzamidine $\mathrm{HCl}, 1.2 \mu \mathrm{g} / \mathrm{ml}$ Phosphoramidon, $1 \mathrm{mg} / \mathrm{ml}$ 1,10-phenanthroline; Bionovas biotechnology, Toronto, Canada) and performed as previously described $^{5,54}$. Western blot analysis was performed using the antibody for calmodulin binding peptide (CBP; Millipore) and halo tag (Promega).

\section{Proximity ligation assay}

Proximity ligation assay was performed with Duolink In Situ Starter Kit (Sigma) according to manufacture's protocol as described previously ${ }^{5}$. The slides were stained with a combination of LSD1 (Cell Signaling Technology), GSK3 $\beta$ (Santa Cruz Biotechnology) antibodies, as well as an IgG control antibody (Sigma) The slides were then examined using a Leica TCS SP2 confocal laser scanning microscope (Leica Microsystems GmbH, Wetzlar, Germany) and the numbers of interaction signal was quantified using the ImageJ software

\section{Immunofluorescence microscopy}

Briefly, After DNA transfection, cells were fixed with $2 \%$ paraformaldehyde at $4{ }^{\circ} \mathrm{C}$ for $30 \mathrm{~min}$ and then incubated for $1 \mathrm{~h}$ at room temperature in blocking buffer (Thermo Fisher Scientific, MA, USA) ${ }^{5}$. Flag and LSD1 staining was performed by incubating cells with mouse monoclonal antibodies raised against Flag (M2, Sigma; 1:100 dilution) and LSD1 (Cell Signaling Technology; 1:100 dilution). After incubation with anti-Alexa Fluor-488 (Invitrogen; 1:100 dilution), slides were mounted with the mounting medium (Sigma Aldrich) and analyzed using a Leica TCS SP2 laser scanning confocal system (Leica Microsystems $\mathrm{GmbH})$. The average integration of fluorescence was quantified with MetaMorph image analysis software (Molecular Devices, LLC., Sunnyvale, CA).

\section{Ki67 immunostaining and BrdU assay}

For BrdU assay, ARK2 cells were treated with BrdU for $2 \mathrm{~h}$ after transfecting with wild-type LSD1 or LSD1 S707A/S711A for $48 \mathrm{~h}$. DNA synthesis activity was measured with BrdU ELISA kit (Roche applied science). For 
Ki67 staining, after tranfecting with wild-type LSD1 or LSD1 (S707A/S711A) in ARK2 cells for $48 \mathrm{~h}^{8}$, Ki67 was stained with an anti-Ki67 antibody (Cell Signaling Technology).

\section{Immunohistochemistry}

This immunohistochemical study complied with the tenets of the Helsinki declaration and was approved by our local Institutional Review Board (No.101-4771B). Formalin-fixed, paraffin-embedded ovarian cancer tissues and endometrial cancer tissue array (UT1002, US Biomax. Inc, Rockville, MD, USA) were sectioned at $4 \mu \mathrm{m}$ thickness and deparaffinized with xylene. Sections were dehydrated through a series of graded ethanol baths and stained with antibodies raised against human LSD1 (Cell Signaling Technology) and GSK3 $\beta$ (Cell Signaling Technology) in an automated immunohistochemical stainer (Leica Bond Polymer Refine Detection Kit; Buffalo Grove, IL, USA) according to the manufacturer's protocol. Hematoxylin was used for counterstaining. In line with previous methodology ${ }^{53}$, a semiquantitative assessment of immunohistochemical staining was performed using a histoscore calculated by multiplying the percentage of tumor cells (from 0 to $100 \%$ ) by their immunointensity (from 0 to 3).

\section{In vivo animal model}

Briefly, after inoculating Mosec/luc cells to C57BL/6 mouse 1 week later ${ }^{52}$, mice were injected intraperitoneally with designated regimens: vehicle control $(20 \%$ Water: 20\% DMSO: 60\% cremophor), LY2090314 (10 mg/kg), SP2509 (10 mg/kg), and LY2090314 plus SP2509 (10 mg/ $\mathrm{kg}$ each) twice a week. Tumor growth was monitored by luciferase activity detected with the Xenogen IVIS Spectrum In Vivo Imaging System (Xenogen Corp., Alameda, CA, USA). Light outputs were quantified using the LivingImage software (Xenogen Corp.).

\section{Acknowledgements}

We are grateful to the Microscope Core Laboratory, Tissue Bank and Center for Advanced Molecular Imaging and Translation, Chang Gung Memorial Hospital, Linkou, Taiwan. This study was financially supported by grants from the Ministry of Science and Technology (106-2314-B-182A-087-MY3 to C.-L.T. 1022628-B-182-016-MY3 and 105-2314-B-182-056 to A.C.; 103-2314-B-182-057-MY3 to T.-H.W.), the Chang Gung Medical Research Foundation (CMRPG3G0371 and CMRPG3F1621/2 to C.-L.T.; CRRPG3D0021/2/3 to A.C.; CRRPG3D0031/2/3 and CMRPG3F2111 to T.-H.W.). Formalin-fixed paraffin-embedded cancer specimens were kindly provided by the Tumor Bank.

\footnotetext{
Author details

${ }^{1}$ Genomic Medicine Research Core Laboratory, Chang Gung Memorial Hospital, Taoyuan, Taiwan. ${ }^{2}$ Department of Obstetrics and Gynecology, Chang Gung Memorial Hospital, Linkou Medical Center and Chang Gung University, Taoyuan, Taiwan. ${ }^{3}$ Department of Pathology, Chang Gung Memorial Hospital, Linkou Medical Center and Chang Gung University, Taoyuan, Taiwan. ${ }^{4}$ Gynecologic Cancer Research Center, Chang Gung Memorial Hospital, Taoyuan, Taiwan
}

Conflict of interest

The authors declare that they have no conflict of interest.

\section{Publisher's note}

Springer Nature remains neutral with regard to jurisdictional claims in published maps and institutional affiliations.

Supplementary Information accompanies this paper at (https://doi.org/ 10.1038/s41389-018-0040-z).

Received: 24 April 2017 Revised: 10 February 2018 Accepted: 20 February 2018

Published online: 29 March 2018

\section{References}

1. Carrigan, P. E., Riggs, D. L., Chinkers, M. \& Smith, D. F. Functional comparison of human and Drosophila Hop reveals novel role in steroid receptor maturation. J. Biol. Chem. 280, 8906-8911 (2005).

2. Baindur-Hudson, S., Edkins, A. L. \& Blatch, G. L. Hsp70/Hsp90 organising protein (hop): beyond interactions with chaperones and prion proteins. Subcell. Biochem. 78, 69-90 (2015).

3. Scheufler, C. et al. Structure of TPR domain-peptide complexes: critical elements in the assembly of the Hsp70-Hsp90 multichaperone machine. Cell 101, 199-210 (2000).

4. Schmid, A. B. et al. The architecture of functional modules in the Hsp90 cochaperone Sti1/Hop. EMBO J. 31, 1506-1517 (2012).

5. Tsai, C. L. et al. Stress-induced phosphoprotein-1 maintains the stability of JAK2 in cancer cells. Oncotarget 7, 50548-50563 (2016).

6. Beraldo, F. H. et al. Stress-inducible phosphoprotein 1 has unique cochaperone activity during development and regulates cellular response to ischemia via the prion protein. FASEB J. 27, 3594-3607 (2013).

7. Wang, T. H. et al. Stress-induced phosphoprotein 1 as a secreted biomarker for human ovarian cancer promotes cancer cell proliferation. Mol. Cell Proteom. 9, 1873-1884 (2010).

8. Tsai, C. L. et al. Secreted stress-induced phosphoprotein 1 activates the ALK2SMAD signaling pathways and promotes cell proliferation of ovarian cancer cells. Cell Rep. 2, 283-293 (2012).

9. Chao, A. et al. Tumor stress-inducedphosphoprotein1 (STIP1) as a prognostic biomarker in ovarian cancer. PLoS ONE 8, e57084 (2013).

10. Chao, A. et al. Immunohistological analysis of stress-induced phosphoprotein 1 in ovarian cancer patients with low serum cancer antigen 125 levels. Taiwan J. Obstet. Gynecol. 52, 185-191 (2013).

11. Cho, H. et al. Expression of stress-inducedphosphoprotein1 (STIP1) is associated with tumor progression and poor prognosis in epithelial ovarian cancer. Genes Chromosomes Cancer 53, 277-288 (2014).

12. Padden, J. et al. Identification of novel biomarker candidates for the immunohistochemical diagnosis of cholangiocellular carcinoma. Mol. Cell Proteom. 13, 2661-2672 (2014)

13. Wang, J. et al. Autocrine and paracrine STIP1 signaling promote osteolytic bone metastasis in renal cell carcinoma. Oncotarget 8, 17012-17026 (2017).

14. Walsh, N. et al. RNAi knockdown of Hop (Hsp70/Hsp90 organising protein) decreases invasion via MMP-2 down regulation. Cancer Lett. 306, 180-189 (2011).

15. Shi, $Y$. et al. Histone demethylation mediated by the nuclear amine oxidase homolog LSD1. Cell 119, 941-953 (2004).

16. Zheng, Y. C. et al. A systematic review of histone lysine-specific demethylase 1 and its inhibitors. Med. Res. Rev. 35, 1032-1071 (2015).

17. Huang, J. et al. p53 is regulated by the lysine demethylase LSD1. Nature $\mathbf{4 4 9}$ 105-108 (2007).

18. Wang, J. et al. The lysine demethylase LSD1 (KDM1) is required for maintenance of global DNA methylation. Nat. Genet. 41, 125-129 (2009).

19. Chen, $C$. et al. Expression of lysine-specific demethylase 1 in human epithelial ovarian cancer. J. Ovarian Res. 8, 28 (2015).

20. Liu, Y. D. et al. Overexpression of lysine-specific demethylase 1 is associated with tumor progression and unfavorable prognosis in chinese patients with endometrioid endometrial adenocarcinoma. Int. J. Gynecol. Cancer 25, 1453-1460 (2015). 
21. Konovalov, S. \& Garcia-Bassets, I. Analysis of the levels of lysine-specific demethylase 1 (LSD1) mRNA in human ovarian tumors and the effects of chemical LSD1 inhibitors in ovarian cancer cell lines. J. Ovarian Res. 6, 75 (2013).

22. Bennesch, M. A., Segala, G., Wider, D. \& Picard, D. LSD1 engages a corepressor complex for the activation of the estrogen receptor alpha by estrogen and CAMP. Nucleic Acids Res. 44, 8655-8670 (2016).

23. Feng, J. et al. Phosphorylation of LSD1 at Ser112 is crucial for its function in induction of EMT and metastasis in breast cancer. Breast Cancer Res. Treat. 159, 443-456 (2016).

24. Nam, H. J. et al. Phosphorylation of LSD1 by PKCalpha is crucial for circadian rhythmicity and phase resetting. Mol. Cell 53, 791-805 (2014).

25. Peng, B. et al. Modulation of LSD1 phosphorylation by CK2/WIP1 regulates RNF168-dependent 53BP1 recruitment in response to DNA damage. Nucleic Acids Res. 43, 5936-5947 (2015).

26. Wang, Q. M., Roach, P. J. \& Fiol, C. J. Use of a synthetic peptide as a selective substrate for glycogen synthase kinase 3. Anal. Biochem. 220, 397-402 (1994).

27. McCubrey, J. A. et al. GSK-3 as potential target for therapeutic intervention in cancer. Oncotarget 5, 2881-2911 (2014).

28. Shakoori, A. et al. Deregulated GSK3beta activity in colorectal cancer: its association with tumor cell survival and proliferation. Biochem. Biophys. Res. Commun. 334, 1365-1373 (2005).

29. Cao, Q., Lu, X. \& Feng, Y. J. Glycogen synthase kinase 3 beta positively regulates the proliferation of human ovarian cancer cells. Cell Res. 16, 671-677 (2006).

30. Farago, M. et al. Kinase-inactive glycogen synthase kinase 3 beta promotes Wnt signaling and mammary tumorigenesis. Cancer Res. 65, 5792-5801 (2005).

31. Wang, Y. et al. Adiponectin modulates the glycogen synthase kinase 3 beta/ beta-catenin signaling pathway and attenuates mammary tumorigenesis of MDA-MB-231 cells in nude mice. Cancer Res. 66, 11462-11470 (2006).

32. Taipale, M., Jarosz, D. F. \& Lindquist, S. HSP90 at the hub of protein homeostasis: emerging mechanistic insights. Nat. Rev. Mol. Cell Biol. 11, 515-528 (2010).

33. Cooper, L. C., Prinsloo, E., Edkins, A. L. \& Blatch, G. L. Hsp90alpha/beta associates with the GSK3beta/axin1/phospho-beta-catenin complex in the human MCF7 epithelial breast cancer model. Biochem. Biophys. Res. Commun. 413 550-554 (2011).

34. Horibe, T., Kohno, M., Haramoto, M., Ohara, K. \& Kawakami, K. Designed hybrid TPR peptide targeting Hsp90 as a novel anticancer agent. J. Transl. Med. 9, 8 (2011).

35. Zhou, A. et al. Nuclear GSK3beta promotes tumorigenesis by phosphorylating KDM1A and inducing its deubiquitylation by USP22. Nat. Cell Biol. 18, 954-966 (2016).

36. Walsh, N. et al. Identification of pancreatic cancer invasion-related proteins by proteomic analysis. Proteome Sci. 7, 3 (2009).

37. Kubota, H. et al. Increased expression of co-chaperone HOP with HSP9O and HSC70 and complex formation in human colonic carcinoma. Cell Stress Chaperon. 15, 1003-1011 (2010).
38. Sun, W. et al. Proteome analysis of hepatocellular carcinoma by twodimensional difference gel electrophoresis: novel protein markers in hepatocellular carcinoma tissues. Mol. Cell Proteom. 6, 1798-1808 (2007).

39. Mattison, S. A., Blatch, G. L. \& Edkins, A. L. HOP expression is regulated by p53 and RAS and characteristic of a cancer gene signature. Cell Stress Chaperon. 22, 213-223 (2017)

40. Sawarkar, R. \& Paro, R. Hsp90@chromatin.nucleus: an emerging hub of a networker. Trends Cell Biol. 23, 193-201 (2013).

41. Kang, K. I. et al. In vivo functional protein-protein interaction: nuclear targeted hsp90 shifts cytoplasmic steroid receptor mutants into the nucleus. Proc. Natl Acad. Sci. USA 91, 340-344 (1994).

42. Langer, T., Rosmus, S. \& Fasold, H. Intracellular localization of the $90 \mathrm{kDA}$ heat shock protein (HSP90alpha) determined by expression of a EGFP-HSP90alphafusion protein in unstressed and heat stressed 3 T3 cells. Cell Biol. Int. 27, 47-52 (2003).

43. Daniel, S. et al. Nuclear translocation of the phosphoprotein Hop (Hsp70/ Hsp90 organizing protein) occurs under heat shock, and its proposed nuclear localization signal is involved in Hsp90 binding. Biochim. Biophys. Acta 1783 1003-1014 (2008)

44. Longshaw, V. M., Chapple, J. P., Balda, M. S., Cheetham, M. E. \& Blatch, G. L. Nuclear translocation of the Hsp70/Hsp90 organizing protein $\mathrm{mSTI1}$ is regulated by cell cycle kinases. J. Cell Sci. 117, 701-710 (2004).

45. Soares, I. N. et al. Regulation of stress-inducible phosphoprotein 1 nuclear retention by protein inhibitor of activated STAT PIAS1. Mol. Cell Proteom. 12, 3253-3270 (2013).

46. Dou, F., Chang, X. \& Ma, D. Hsp90 maintains the stability and function of the tau phosphorylating kinase GSK3ß. Int. J. Mol. Sci. 8, 51 (2007).

47. Muller, P. et al. C-terminal phosphorylation of Hsp70 and Hsp90 regulates alternate binding to co-chaperones CHIP and HOP to determine cellular protein folding/degradation balances. Oncogene 32, 3101-3110 (2013).

48. Sorna, V. et al. High-throughput virtual screening identifies novel N'-(1-phenylethylidene)-benzohydrazides as potent, specific, and reversible LSD1 inhibitors. J. Med. Chem. 56, 9496-9508 (2013).

49. Sankar, S. et al. Mechanism and relevance of EWS/FLI-mediated transcriptional repression in Ewing sarcoma. Oncogene 32, 5089-5100 (2013).

50. Fiskus, W. et al. Highly effective combination of LSD1 (KDM1A) antagonist and pan-histone deacetylase inhibitor against human AML cells. Leukemia $\mathbf{2 8}$ 2155-2164 (2014)

51. Stazi, G., Zwergel, C., Valente, S. \& Mai, A. LSD1 inhibitors: a patent review (2010-2015). Expert Opin. Ther. Pat. 26, 565-580 (2016).

52. Kao, C. et al. Phosphorylation of signal transducer and activator of transcription 1 reduces bortezomib-mediated apoptosis in cancer cells. Cell Death Dis. 4, e512 (2013)

53. Chao, A. et al. Regulation of ovarian cancer progression by microRNA-187 through targeting Disabled homolog-2. Oncogene 31, 764-775 (2011).

54. Chao, A. et al. Lysine-specific demethylase 1 (LSD1) destabilizes p62 and inhibits autophagy in gynecologic malignancies. Oncotarget 8, 74434-74450 (2017). 